\title{
Policy Impacts on Schooling Gender Gaps in Developing Countries: The Evidence and a Framework for Interpretation*
}

By

\author{
Peter Glick \\ Cornell University \\ Room 3M2 MVR Hall \\ Ithaca NY 14853 \\ (607) 254-8782 \\ pjg4@cornell.edu
}

February 2008

*This is an expanded version of a paper that is forthcoming in World Development

ISSN 1936-5071 


\section{Summary}

In many regions of the developing world girls continue to receive less education than boys. This paper reviews the evidence on the effects of policies in the education sector and outside it on household schooling investments in girls and boys, distinguishing between policies that are ostensibly gender neutral and those that explicitly target girls. It is frequently (but certainly not universally) found that the demand for girl's schooling is more responsive than boys' to gender neutral changes in school cost or distance as well as quality. Although these patterns can be interpreted in terms of parental preferences, this paper shows that they can also plausibly be explained within a human capital investment framework through assumptions about the nature of schooling cost and returns functions. Among these policies, increasing the physical accessibility of schools emerges as a measure that may result in disproportionate enrollment gains for girls. Where gender gaps are large or persistent, however, direct targeting of girls is probably necessary. Formal evidence from a number of demand or supply side interventions, including subsidies to households and to schools to enroll girls and the provision of girls-only schools, suggests the potential for targeted measures to yield substantial gains for girls. Many other policies, such as subsidized childcare or flexible school scheduling that address the opportunity costs of girls' time, hold promise but for the most part have yet to be subject to rigorous assessment. The paper discusses methodological problems in such assessments and concludes with suggestions for future research on policies to close schooling gender gaps.

Keywords: education, gender, human capital investments 


\section{Table of Contents}

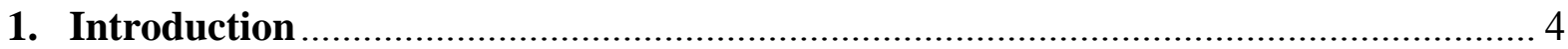

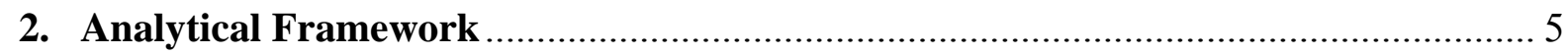

Gender differences in response to policy changes ......................................... 7

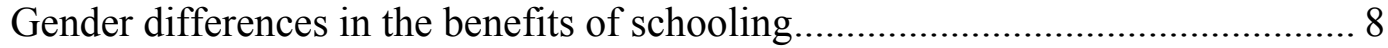

Differences in schooling cost functions ......................................................... 9

Discontinuous schooling benefits or costs ................................................. 11

Differences in school dropout/continuation probabilities ................................ 12

3. Evidence for Impacts of Policies on Girls' and Boys' Schooling ............................ 13

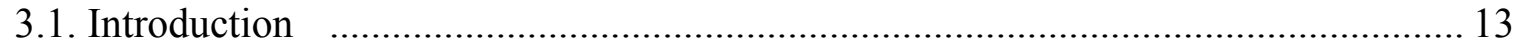

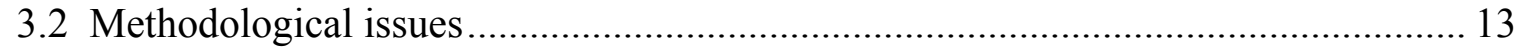

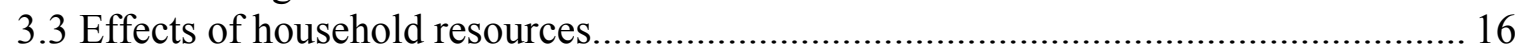

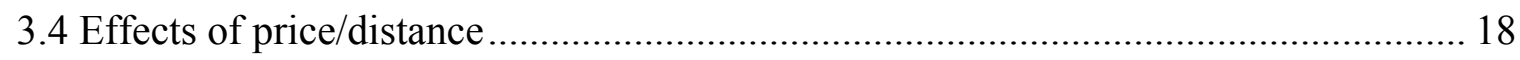

Evidence from demand studies ............................................................... 18

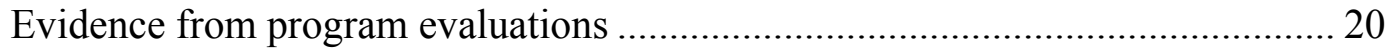

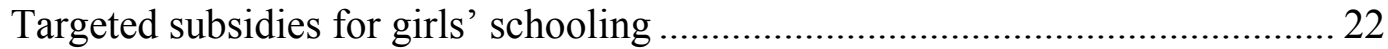

3.5 Characteristics of schools and the learning environment....................................... 23

Aspects of school quality/environment that are similar for girls and boys.......... 24

Aspects of school quality/environment that are different for girls and boys ........ 25

3.6 Policies that address the opportunity costs of educating girls.................................29

3.7 Public information campaigns to promote girls' schooling ..................................... 30

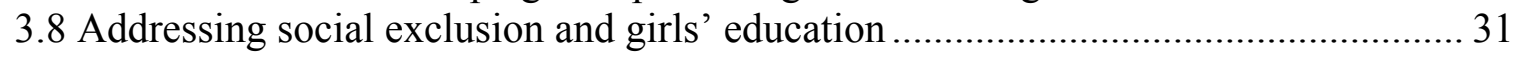

3.9 Labor market policies.................................................................................. 32

Implications of female and male patterns of labor market activity for

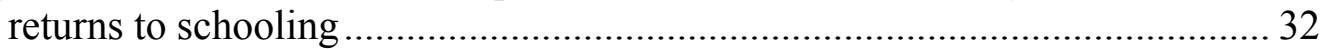

Gender discrimination in the labor market....................................................... 35

Income and time allocation effects of women's employment .......................... 37

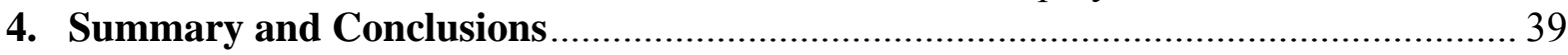

4.1 Implications for policy to close gender schooling gaps .................................... 39

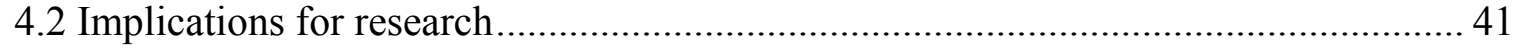

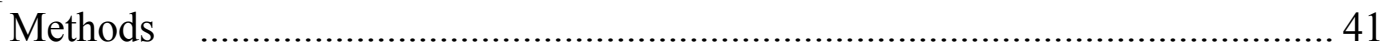

Questions for future research ............................................................... 43

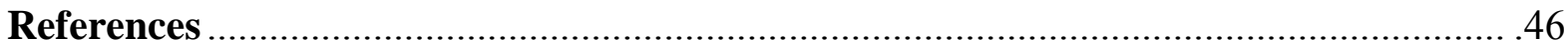

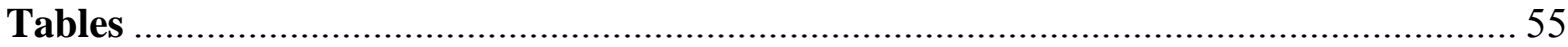

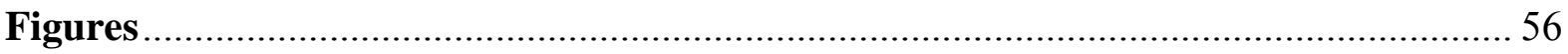




\section{Introduction}

The positive effects of education on economic growth and individual incomes and welfare are widely, even universally, recognized. It is also widely recognized that there are particular benefits to investing in female schooling due to externalities such as improved child nutrition and schooling and reduced fertility (Schultz 2002). These economic efficiency arguments add to the strong equity arguments for increasing female schooling, and through this, women's economic opportunities and social status, in areas where girls have traditionally been disadvantaged in access. Achieving gender equality in education is included among the Millennium Development Goals and many developing country governments now officially recognize this goal as a priority.

Much progress toward gender equity in education has already been made in the last several decades (World Bank 2001; Lockheed and Lewis 2006). In some regions, male and female equality with respect to enrollment ratios has largely been attained; in many Latin American countries, girl's secondary enrollments now actually exceed boys'. Still, as shown in Table 1, significant pro-male gender gaps remain in other regions, notably sub-Saharan Africa, South Asia, and the Middle East. In Africa, the ratio of girls to boys in primary school is $86 \%$ and in secondary school is just 75\%. In South Asia the analogous figures are $85 \%$ and $81 \%$. Regional averages also hide important variations. Within Africa, for example, gender disparities are particularly large in many West African countries. Notably, the Table indicates that regions where gender gaps are largest also tend to be where overall (male and female) enrollments are low. ${ }^{1}$

An important agenda for research, therefore, is to identify policies that would lead to gender parity in education in environments where gaps are large or persistent. This paper considers what research to date can tell us about the impacts on girls' (and boys') schooling of a range of education policies, including those related to price, accessibility, and school quality, as well as other policies that might alter household schooling investments by affecting the costs and returns to these investments. To help interpret the findings in the literature I begin by setting out a simple conceptual framework of parental investment in girls' and boys' human capital. The discussion makes the distinction between explanations of why levels of investments in girl's schooling might be lower than boys' (for example, higher opportunity costs of girls' time) and explanations of why changes in schooling in response to policies such as fee reductions or quality improvements might differ for girls and boys. The two are not the same, and it is the latter, of course, that is important for determining the appropriate policies to close education gender gaps. Different model assumptions provide alternative explanations of why impacts of

\footnotetext{
${ }^{1}$ One can also compare genders with respect to direct education outcome measures, namely, test scores. Overviews of the developing country evidence, both from cross-country studies using standardized tests and from individual country analyses (based typically on pass rates on secondary leaving exams), provide a mixed picture (see National Research Council 2003; Oxfam 2003). In some countries or subjects boys do better; in others, girls. Where dropout or non-enrollment are significant, however, school based samples of test-taking children are not representative of all children, and for gender comparisons the problem is especially acute if girls are less likely to start school or more likely to drop out early. This implies that there will be greater selectivity into the testing sample for girls than for boys, and this will likely be associated with unmeasured ability that affects test performance, biasing estimates of gender differences.
} 
household income, school price, and school quality might be larger for girls' schooling than boys', patterns that occur frequently in the empirical literature.

The paper then considers evidence for two basic types of policies that may differentially affect the schooling of girls and boys: those that are 'gender neutral', i.e. that do not specifically target female (or male) schooling returns or costs; and those that are gender-targeted, i.e., that attempt to alter the costs or benefits of girls' schooling relative to boys'. The evidence I will discuss comes primarily from econometric analyses of schooling demand using representative household surveys, often linked to surveys recording local school characteristics. In addition, a number of evaluations of specific interventions, frequently using randomized designs, have been carried out with gender as a focus either of the interventions themselves or of the measured outcomes. By and large I do not delve into the large body of non-experimental project evaluations that consider gender-focused interventions or outcomes, because few of these have been statistical or carried out rigorously enough to permit reliable inferences (few, for example, collect baseline information; see Kane 2004 for a review). Nevertheless, some such evidence is brought to bear when discussing certain policies that have apparently not been widely assessed by more formal means.

Finally, policies not directly concerned with education, notably those involving the labor market and the market for childcare services, may affect schooling incentives and may do so differently for girls and boys. In particular, the potential impacts of labor market conditions and policies on investments in girls' education are quite complex, and therefore considerable attention is given to this issue. In addition to a conceptual discussion I review the (more limited) empirical evidence on impacts of non-education policies.

I should make clear here that it is not the purpose of this paper to lay out the theoretical and empirical justifications for investing in girls' education. These justifications, including in particular the potentially large externalities with respect to children's welfare and economic growth, have been presented many times, most incisively by T.P. Schultz (1993, 2002). The focus here is instead on understanding parental schooling decisions-i.e., the private demand for schooling of girls and boys - which by definition do not incorporate externalities, and how these decisions respond to policies.

The remainder of the paper is structured as follows. The next section presents the model of household schooling investments. This is followed in Section 3 by a review of the evidence on gendered impacts of policies. Section 4 summarizes and discusses implications for policy as well as for future research.

\section{Analytical Framework}

The model is a general two-period model of parental investment in daughters' and sons' human capital. ${ }^{2}$ The parents work in the first period and depend on support from their children in

\footnotetext{
${ }^{2}$ This framework is well suited to thinking about initial enrollments and continuation among younger children; for those in adolescence, the process becomes more complex as the children themselves will often take a more active role in decisions about their schooling.
} 
the second. For a household with a boy and a girl child, the lifetime utility of the parents is written as:

$$
\mathrm{U}=\mathrm{U}_{1}\left(\mathrm{C}_{1}\right)+\mathrm{U}_{2}\left(\mathrm{C}_{2}, \mathrm{~W}_{\mathrm{g}}, \mathrm{W}_{\mathrm{b}}\right)
$$

where $\mathrm{C}_{\mathrm{t}}$ is consumption in period $\mathrm{t}$ and $\mathrm{W}_{\mathrm{g}}$ and $\mathrm{W}_{\mathrm{b}}$ are second period wealth of the girl and boy, respectively. First period utility of the parents depends on their consumption in that period, while second period utility is a function of consumption via transfers from children's wealth as well direct utility benefits to parents from their children having more wealth, i.e., having higher welfare. Thus the framework encompasses parental schooling decisions based on either selfinterest (desire for remittances) or altruism toward children. ${ }^{3}$

A child's wealth in period two is a function of the first period investment in her schooling $\left(\mathrm{S}_{\mathrm{i}}\right)$ as well as first period labor in productive work $\left(\mathrm{L}_{\mathrm{i}}\right)$ such as family farming or other activities that leads to the accumulation of remunerative skills:

$$
\mathrm{W}_{\mathrm{i}}=\mathrm{W}\left(\mathrm{S}_{\mathrm{i}}, \mathrm{L}_{\mathrm{i}}\right), \quad \mathrm{i}=\mathrm{b}, \mathrm{g}
$$

Since both early work experience and schooling increase adult wealth, and since the child's time constraint implies that an increase in one activity reduces time in the other, children's work and schooling represent competing first period investment choices for the household.

If parents do not have access to credit to enable them to allocate consumption over time, first period consumption depends on income in that period net of school expenses:

$$
C_{1}=Y_{p}+Y_{g}\left(L_{g}\right)+Y_{b}\left(L_{b}\right)-P_{g} S_{g}-P_{b} S_{b}
$$

where $Y_{p}$ is the income of the parents, $Y_{g}$ and $Y_{b}$ represent the contributions of the girl and boy to first period household income (hence are functions of their labor $\mathrm{L}_{\mathrm{g}}$ and $\mathrm{L}_{\mathrm{b}}$ ), and $\mathrm{P}_{\mathrm{g}}$ and $\mathrm{P}_{\mathrm{b}}$ are the direct or monetary costs per unit of schooling for each child. Since the household is unable to borrow to finance school investments, these must be financed by reductions in first period consumption. Second period consumption depends on transfers, which are shares $r_{b}$ and $r_{g}$ of son's and daughter's wealth, i.e., $\mathrm{C}_{2}=\mathrm{r}_{\mathrm{b}} \mathrm{W}_{\mathrm{b}}+\mathrm{r}_{\mathrm{g}} \mathrm{W}_{\mathrm{g}}$. For the first period parents must decide on the allocation of each child's time between schooling and work activities as well as leisure. That is, they choose $S_{g}$ and $S_{b}$ as well as $L_{g}$ and $L_{b}$ to maximize lifetime utility subject to the first period budget constraint as well as (implicitly) the time constraint of each child. Substituting for $\mathrm{C}_{1}$ and $\mathrm{C}_{2}$ in Eq. (1):

$$
\begin{aligned}
\operatorname{Max} L=U_{1}\left(Y_{p}+Y_{g}\left(L_{g}\right)+Y_{b}\left(L_{b}\right)-P_{g} S_{g}-P_{b} S_{b}\right) \\
+U_{2}\left(\left[r_{g} W_{g}\left(S_{g}, L_{g}\right)+r_{b} W_{b}\left(S_{b}, L_{b}\right)\right], W_{g}\left(S_{g}, L_{g}\right), W_{b}\left(S_{b}, L_{b}\right)\right)
\end{aligned}
$$

\footnotetext{
${ }^{3}$ Parental altruism could in principle extend toward their children's children, in which case schooling effects on the non-market productivity of a daughter (specifically, on her ability to insure the health and well being of her own children) may enter parental utility as a further benefit of schooling. Following most treatments in the literature, this factor is ignored. This assumption is discussed in more detail below in Section 3.9.
} 
After rearranging terms, the first order conditions for girl's and boy's schooling are:

$$
\begin{aligned}
& \frac{\partial U_{2}}{\partial C_{2}} r_{g} \frac{\partial W_{g}}{\partial S_{g}}+\frac{\partial U_{2}}{\partial W_{g}} \frac{\partial W_{g}}{\partial S_{g}}=\frac{\partial U_{1}}{\partial C_{1}}\left(P_{g}-\frac{\partial Y_{g}}{\partial L_{g}} \frac{\partial L_{g}}{\partial S_{g}}\right)+\frac{\partial U_{2}}{\partial C_{2}} r_{g}\left(-\frac{\partial W_{g}}{\partial L_{g}} \frac{\partial L_{g}}{\partial S_{g}}\right) \\
& \frac{\partial U_{2}}{\partial C_{2}} r_{b} \frac{\partial W_{b}}{\partial S_{b}}+\frac{\partial U_{2}}{\partial W_{b}} \frac{\partial W_{b}}{\partial S_{b}}=\frac{\partial U_{1}}{\partial C_{1}}\left(P_{b}-\frac{\partial Y_{b}}{\partial L_{b}} \frac{\partial L_{b}}{\partial S_{b}}\right)+\frac{\partial U_{2}}{\partial C_{2}} r_{b}\left(-\frac{\partial W_{b}}{\partial L_{b}} \frac{\partial L_{b}}{\partial S_{b}}\right)
\end{aligned}
$$

These imply that parents invest in the schooling of each child until the marginal utility equals marginal cost. The marginal utility (or marginal benefit) of schooling depends on transfers from the additions to the child's wealth that result from another year in school (first term on the left hand side) as well as on the direct effect on parental utility of the child having more wealth (second term on LHS).

Marginal costs of schooling involve, first, the reduction in current consumption incurred by increasing the level of schooling, captured in the first term on the right hand side. This involves both direct costs $\mathrm{Pi}$ as well as indirect costs since additional time in school reduces the child's time in productive activities (i.e., $\partial \mathrm{Li} / \partial \mathrm{Si}<0$ ), reducing household income. Second, the reduction in child labor in period one also means that the level of accumulated skills in income generating activities will be lower, cet. par. reducing second period wealth. This in turn reduces future transfers from the child (shown in the last term on the RHS). ${ }^{4}$

Plausible assumptions in this or similar frameworks (Alderman and King 1998; Rosenzweig and Schultz 1982) can explain why investments in girls' human capital are often lower than boys'. Holding other factors to be the same for both sexes, daughters will receive less schooling than sons if the remittance rate $r_{i}$ is higher out of son's wealth $\left(r_{b}>r_{g}\right)$, if the marginal returns to schooling in the labor market are everywhere higher for boys than girls $\left(\partial \mathrm{W}_{\mathrm{b}} / \partial \mathrm{S}_{\mathrm{b}}>\right.$ $\partial \mathrm{W}_{\mathrm{g}} / \partial \mathrm{S}_{\mathrm{g}}$ ), or if the marginal cost of schooling is everywhere higher for girls (say because the demand for their labor in childcare or other domestic work raises the value of their time in the household). Greater schooling for boys can also arise, of course, from the preferences of parents if they simply value boy's human capital more than girls, or if they value the future utility, hence wealth, of boys more.

\section{Gender differences in response to policy changes}

To yield gender differences in changes in the level of schooling in response to policies that alter education costs or benefits, it is usually necessary to put more structure on the model. In a framework treating schooling as consumption, assumptions about parental preferences for girls and boys could generate gender differences in the responses to policies that alter education costs or returns. In the human capital investment framework, differential responses can arise

\footnotetext{
${ }^{4}$ The reduction in wealth also reduces $2^{\text {nd }}$ period utility of the parents, adding to the marginal cost (not shown).
} 
from the presence of nonlinearities or discontinuities in the cost or benefits schedules. ${ }^{5}$ Several possibilities are discussed in what follows. The purpose of this presentation, it should be emphasized, is not to generate specific predictions but rather to provide a framework for interpreting findings in the literature to be discussed in Section 3.

\section{Gender differences in the benefits of schooling}

Consider first the case of differences in schooling benefits for girls and boys. Assume conventional concave earnings functions such that marginal returns in the labor market are positive but declining in the level of human capital, that is, $\mathrm{W}_{\mathrm{i}}=\alpha_{1} \mathrm{~S}_{\mathrm{i}}-\alpha_{2} \mathrm{~S}_{\mathrm{i}}^{2}\left(\alpha_{1}>0, \alpha_{2}>0\right)$. Given remittance rates $r_{b}$ and $r_{g}$ for boys and girls, the parental marginal returns to schooling, which are assumed for this example to include only the change in parents' second period consumption from an additional year of the child's schooling, are $r_{b}\left(\partial W_{b} / \partial S_{b}\right)=r_{b} \alpha_{1}-2 r_{b} \alpha_{2} S_{b}$ for boys and $r_{g}\left(\partial \mathrm{W}_{\mathrm{g}} / \partial \mathrm{S}_{\mathrm{g}}\right)=\mathrm{r}_{\mathrm{g}} \alpha_{1}-2 \mathrm{r}_{\mathrm{g}} \alpha_{2} \mathrm{~S}_{\mathrm{g}}$ for girls. ${ }^{6}$ If remittances out of son's income are greater than out of daughter's $\left(r_{b}>r_{g}\right)$, the marginal benefits are higher for boys than girls but also decline more rapidly for boys as schooling increases (the slopes of the marginal benefits are $2 \mathrm{r}_{\mathrm{b}} \alpha_{2}$ and $-2 \mathrm{r}_{\mathrm{g}} \alpha_{2}$ for boys and girls, respectively). The same girl-boy differences in returns would result from discrimination in pay that makes the earnings of women some fraction of those of men, or from lower expected labor force participation or labor supply of girls. ${ }^{7,8}$ A school environment that is more conducive to boys' learning could also yield higher marginal benefits curves for boys, by making the addition to human capital from a year of schooling larger for them than for girls.

\footnotetext{
${ }^{5}$ Clearly the consumption and investment perspectives are not mutually exclusive, and any direct consumption value of children's human capital could be incorporated into 'benefits'. The model, however, does not incorporate differing preferences of mothers and fathers for girls' and boys' education. If these preferences differ, policies that increase women's power over household education decisions will affect the gender balance in school investments, as discussed below in section 3.9 .

${ }^{6}$ For marginal benefits to involve only these terms requires not only that parents have purely investment motives but also that they can borrow to finance education investments. Otherwise, as evident from Eqs. (4), schooling marginal benefits (and marginal costs) will also depend on the marginal utility of consumption in each period $\left(\partial \mathrm{U}_{\mathrm{t}} / \partial \mathrm{C}_{\mathrm{t}}\right)$, or in other words, on the marginal rate of intertemporal substitution in consumption, which is an endogenous function of the level of first period schooling investments. If parents have access to credit, however, they will invest until monetary returns $\mathrm{r}_{\mathrm{i}}\left(\partial \mathrm{W}_{\mathrm{i}} / \partial \mathrm{S}_{\mathrm{i}}\right)$ equal $\mathrm{P}_{\mathrm{i}}(1+\mathrm{i})$ (ignoring indirect costs), where $i$ is the interest rate. The assumption of access to credit simplifies the exposition but does not qualitatively affect the discussion.

${ }^{7}$ As discussed below in Section 3.9, even if increments to human capital of women are rewarded equivalently to that of men in terms, say, of hourly pay, investment in an additional year of schooling will result in a smaller increase in (expected) lifetime earnings for girls if they are less likely to be in the labor force or if they work over a smaller portion of their lifetimes than boys will.

${ }^{8}$ As Schultz (2002) points out, even if daughters remit less than sons, instead giving their earnings to their spouse's family, there could nevertheless be high returns to educating girls through effects in the marriage market (e.g., (women with high earning potential are more attractive to potential mates). On the other hand, if girls' future labor force participation is not likely, potential brides will more likely to be valued for their domestic skills. Parents may feel that some minimal schooling will increase these skills but that there are few benefits thereafter. Therefore, given the likely inverse relation of time devoted to schooling and time in domestic work, accumulation of this form of human capital may be perceived to be inversely related to the level of education beyond some point. Via negative effects on bride price this would tend to reduce the household's returns to educating girls.
} 
Figure 1 shows the total and marginal benefit and cost functions for this case. Equivalent linear cost functions for girls and boys are assumed for the exposition. ${ }^{9}$ As illustrated by the bottom panel, equality of marginal costs and benefits implies lower optimal investment in girls' schooling $\left(\mathrm{S}_{\mathrm{B}}>\mathrm{S}_{\mathrm{G}}\right)$, because their marginal benefits function is lower. But a gender neutral fall in school costs, represented in the bottom panel by the shift to the dotted $\mathrm{MC}^{\prime}$ line, increases optimal schooling for girls more than boys (compare $\mathrm{S}_{\mathrm{G}}{ }^{\prime}-\mathrm{S}_{\mathrm{G}}$ and $\mathrm{S}_{\mathrm{B}}{ }^{\prime}-\mathrm{S}_{\mathrm{B}}$ ). Because marginal benefits decline more slowly for girls, the adjustment needed to restore equilibrium after the shift in the marginal cost function is larger. A similar outcome would occur as a result of a nongender targeted improvement in returns that shifted up the marginal benefits for both girls and boys. ${ }^{10}$ Of course, if the benefits functions had different shapes such that marginal benefits were falling faster for girls than boys, these gender differences in impacts would be reversed.

\section{Differences in schooling cost functions}

Gender differences in responses to policies can also arise from differences in schooling cost functions. What is required is for the marginal costs of schooling to be increasing at different rates for girls and boys. If families are credit constrained and thus have to finance education through reductions in other first period expenditures, marginal costs may increase via diminishing marginal utility of first period consumption, which causes the value of forgone consumption to rise at the margin as schooling increases and consumption falls. Further, fees and other direct school costs are usually significantly greater at higher levels of schooling. Finally, opportunity costs in terms of foregone child earnings or household production will increase with the duration of schooling simply because as children mature into adolescence and beyond their productivity in these activities increases.

However, while these factors would make schooling marginal cost curves slope upwards, they would not necessarily do so differently for girls and boys. Reductions in current consumption or increases in the cost of funds as the level of schooling increases, as well as increases in direct school expenses, should be similar for girls and boys. On the other hand, it is possible for opportunity costs in terms of foregone household production to rise faster with schooling for boys than girls. For example, if only boys are permitted to work outside the home and the labor market values increasing maturity or strength more than girls' activities within the home do, potential earnings and thus the opportunity cost of not working will rise more quickly

\footnotetext{
${ }^{9}$ This model is essentially the same as Garg and Morduch (1996)'s model of child health investments. They focus on gender differences in responses to changes in income, a topic I discuss below in section 3.3.

${ }^{10}$ This refers to boy-girl differences in absolute changes (e.g., in years of school), not proportional changes or elasticities. This is done because, first, most of the econometric literature reviewed below reports absolute changes rather than elasticities. Second, whether differing boy-girl response elasticities imply a reduction in the gender gap is ambiguous because it depends on whether the gap is defined in relative terms, as the ratio of boys' to girls' enrollments for example, or in absolute terms, as the percentage point gap in enrollment. If girls' initial schooling is low, proportional increases will tend to be large for them because the base is small; a policy of equal absolute changes for girls and boys would yield larger proportional enrollment gains for girls and reduce the relative gender gap but leave the absolute or percentage point gap unchanged. In contrast, a larger absolute change for girls will always reduce the gap whether measured in relative or absolute terms.
} 
for boys than girls as both get older, or equivalently as the duration and level of schooling increases.

The foregoing relies on a direct association of labor productivity and age or maturity and is plausible because older children are more developed emotionally and physically. However, differentially increasing opportunity costs could also arise from the fact that children's work experience, like schooling, increases their stock of human capital, hence their future incomes (i.e., $\partial \mathrm{W}_{\mathrm{i}} / \partial \mathrm{L}_{\mathrm{i}}>0$ ) Since attending school reduces the time available for work activities, more years in school means less accumulated work experience. As described earlier, this reduction in experience cet. par. has a negative impact on later wealth, which adds to the marginal cost of schooling. Ignoring impacts of work on current consumption, the marginal cost (RHS of equations $4 \mathrm{a}$ and $4 \mathrm{~b})$ is thus $\mathrm{MC}_{\mathrm{i}}=\mathrm{P}-\mathrm{r}_{\mathrm{i}}\left(\partial \mathrm{W}_{\mathrm{i}} / \partial \mathrm{L}_{\mathrm{i}}\right)\left(\partial \mathrm{L}_{\mathrm{i}} / \partial \mathrm{S}_{\mathrm{i}}\right)$ Assume that first period work experience and schooling are separable in the production of human capital and that experience increases wealth at a decreasing rate, i.e., $\mathrm{W}_{\mathrm{i}} \mid \mathrm{S}_{\mathrm{i}}=\beta_{1 \mathrm{i}} \mathrm{L}_{\mathrm{i}}+\beta_{2 \mathrm{i}} \mathrm{L}_{\mathrm{i}}^{2}, \beta_{1 \mathrm{i}}>0, \beta_{2 \mathrm{i}}<0$, and $\partial \mathrm{W}_{\mathrm{i}} / \partial \mathrm{L}_{\mathrm{i}}=\beta_{1 \mathrm{i}}$ $+2 \beta_{2 \mathrm{i}} \mathrm{L}_{\mathrm{i}}$. To simplify, also assume (innocuously) that children's time $\mathrm{T}_{\mathrm{i}}$ is allocated only between school and labor, i.e., $\mathrm{T}_{\mathrm{i}}=\mathrm{S}_{\mathrm{i}}+\mathrm{L}_{\mathrm{i}}$ so that an increase in school attendance reduces work time by an equivalent amount $\left(\partial \mathrm{L}_{\mathrm{i}} / \partial \mathrm{S}_{\mathrm{i}}=-1\right)$. Substituting for the marginal benefit of labor $\partial \mathrm{W}_{\mathrm{i}} / \partial \mathrm{L}_{\mathrm{i}}$ in the marginal cost function yields $\mathrm{MC}_{\mathrm{i}}=\mathrm{P}+\mathrm{r}_{\mathrm{i}}\left(\tau-2 \beta_{2 \mathrm{i}} \mathrm{S}_{\mathrm{i}}\right)$ where $\tau=\beta_{1 \mathrm{i}}+2 \beta_{2 \mathrm{i}} \mathrm{T}_{\mathrm{i}}$. Because of the concavity of the returns function for non-school human capital $\left(\beta_{2 i}<0\right)$, the marginal cost of schooling is increasing in years of education, as shown for boys and girls in Figure 2. This occurs because the foregone benefits from additions to children's work experience are larger at greater years of school (i.e., at fewer years of 1st period work).

In the case shown marginal costs are depicted as being higher for girls, reflecting (say) the strong demand for their time in household work, but they are rising faster for boys due to greater concavity of the returns to first period experience function for boys. The latter is possible because of differences in the types of work in which girls and boys engage, though the assumption that boy's costs are more concave is arbitrary. Because marginal costs are everywhere higher for girls, investment in their schooling is lower than in boys'. However, since their marginal costs are rising less quickly than boys', restoring equality of marginal costs and benefits after a gender neutral proportional increase in the returns to schooling, shown by the dotted line, requires a larger increase in schooling for girls. ${ }^{11}$ A gender neutral reduction in school price would also lead to this outcome. ${ }^{12}$

\footnotetext{
${ }^{11}$ The quadratic assumption for returns in Figure 2 adds to the difference in girls' and boys' responses but is not required for it. Although the function depicted is the same for girls and boys, a proportional increase in (total) quadratic benefits shifts up marginal benefits more at lower S, hence more for girls. Qualitatively, however, the same outcome would occur if returns were linear.

${ }^{12}$ As noted, for girls first period non-school experience may consist of time spent acquiring domestic skills. Rather than leading to future transfers to parents from labor market earnings, this may bring a higher bride price if young women with strong domestic skills are more highly valued as wives. The perceived marginal costs of schooling would then be calculated as reductions in bride price resulting from reductions in this experience. Obviously this could lead to marginal cost functions quite different from that for boys, whose work experience may instead be in farming or the labor market.
} 


\section{Discontinuous schooling benefits or costs}

Another possible source of differential male-female impacts of education policies is the presence of discontinuities in either the benefits or costs of schooling. It is not difficult to come up with plausible examples of either. Discontinuities in benefits will occur if primary or secondary completion and receipt of a diploma are requirements for entry into well-paid formal (or possibly, public) sector employment. This 'sheepskin effect' shifts up the earnings function at specific years of schooling. For the case of a premium to primary completion, the marginal benefits to schooling would appear as in Figure 3. The earnings function depicted is $\mathrm{W}_{\mathrm{i}}=(1$ $\mathrm{G})\left[\alpha_{1 \mathrm{i}} \mathrm{S}_{\mathrm{i}}+\alpha_{2 \mathrm{i}} \mathrm{S}_{\mathrm{i}}^{2}\right]+\mathrm{G} \theta\left[\alpha_{1 \mathrm{i}} \mathrm{S}_{\mathrm{i}}+\alpha_{2 \mathrm{i}} \mathrm{S}_{\mathrm{i}}^{2}\right], \alpha_{1 \mathrm{i}}>0, \alpha_{2 \mathrm{i}}<0$, where $\mathrm{G}$ is a 0,1 indicator of primary completion and $\theta$ is the premium to primary completion. The figure also shows, as before, marginal costs higher for girls than boys, though here the marginal costs are linear in S; no assumption is made about the curvature of the cost function. There is a large initial gender gap in schooling, reflecting in part that the optimizing level for girls is on the lower, pre-primary completion portion of the benefits schedule. A gender neutral increase in the returns to schooling, shown by the dotted marginal benefit lines, results in a larger increase in girls' years of schooling than boys' because the new equilibrium for girls is on the higher (post-primary returns) portion of the curve. For the same reason, a gender neutral reduction in school costs would also raise girls' schooling more than boys'.

Discontinuities in costs can arise from the pattern noted above of household school expenses rising with each change in school level, e.g., primary to secondary. This may be due to higher school fees and textbook requirements as well as higher transportation costs. With respect to the latter, secondary schools, for example, serve a wider catchment area than primary schools, hence on average are further away from households. This implies an increase in travel expenses and also in opportunity costs through increased travel time (or even, the need to pay for boarding at school). Marginal costs would then look as in Figure 4, where the discontinuity occurs after 6 years of school, i.e., at the start of secondary school. These costs do not differ by gender, but as in several earlier examples the benefits to schooling are assumed higher for males. Because of this the initial optimal amount of schooling for boys exceeds completed primary, while girls receive only a primary education: beyond 6 years, their marginal benefits are below the secondary school marginal costs. Hence this model of gender differences in schooling benefits with discontinuous costs provides a plausible explanation for the frequently observed pattern of lower continuation rates to secondary school for girls than boys.

In contrast to the other models discussed, in this model policies that alter schooling benefits and (secondary) school costs yield larger changes in boys' schooling. The figure illustrates with an improvement in returns. Boys move along the secondary schooling marginal cost schedule to $\mathrm{S}_{\mathrm{B}}$.' For girls, whose initial marginal benefits are lower than boys', there is no increase because an improvement in marginal benefits after 6 years that is proportionately similar to boys' is still not enough to induce investments beyond primary, i.e., marginal benefits remain below marginal cost. Similarly, a policy that reduced secondary school costs equally for girls and boys may lead to more schooling for boys but have no effect on girls: specifically, given the initial benefits schedules, a reduction that is less than or equal to the interval $a-b$ will leave girls' schooling unchanged. 


\section{Differences in school dropout/continuation probabilities}

Finally, gender differences in school continuation probabilities can lead to differences in responses to changes in school costs or returns. Academic performance (hence school progression or withdrawal) may differ for girls and boys because of classroom factors that impinge on girls' ability to learn, such as lack of encouragement of girls on the part of teachers. Or, if the opportunity cost of girls' time is higher due to the demand for their labor in the home, they may have fewer hours for schoolwork or attend class less regularly than boys. This could lead to a higher likelihood of academic failure and an inability to complete (say) the primary cycle or meet entrance requirements for secondary school.

Since academic success or failure cannot be predicted with certainty, risk becomes a factor in parental decisions about investing in their children's education. Especially when schooling returns are discontinuous, this can lead to large differences by gender in both the level of schooling and in the response to policies. To illustrate, Figure 5 presents a strong version of returns discontinuity such that there are no labor market benefits to schooling until a primary diploma is obtained. Therefore marginal benefits are zero until $\mathrm{S}_{\mathrm{i}}=6$ and positive and (we will also assume) declining thereafter. Letting $\mathrm{Gg}_{\mathrm{g}}$ and $\mathrm{Gb}$ represent, respectively, the female and male probabilities of completing primary school, expected marginal labor market returns are therefore $\mathrm{G}_{\mathrm{g}}\left(\zeta_{1 \mathrm{i}} \mathrm{S}_{\mathrm{i}}^{\mathrm{s}}+\zeta_{2 i} \mathrm{~S}_{\mathrm{i}}^{\mathrm{s}}\right)$ for girls and $\mathrm{G}_{\mathrm{b}}\left(\zeta_{1 \mathrm{i}} \mathrm{S}_{\mathrm{i}}^{\mathrm{s}}+\zeta_{2 \mathrm{i}} \mathrm{S}_{\mathrm{i}}^{\mathrm{s}}\right)$ for boys, where $\mathrm{S}_{\mathrm{i}}^{\mathrm{s}}=$ years of secondary (or more generally, post-primary) schooling. The figure depicts the case where $\mathrm{Gg}_{\mathrm{g}}<\mathrm{Gb}$. Since girls' probability of primary completion is lower than boys', the expected value of the benefits of schooling is lower for girls. In addition, because of the difference in opportunity cost, marginal costs are higher for girls. The household invests in schooling of the boy to $\mathrm{S}_{\mathrm{B}}$. But given both higher marginal costs and lower expected marginal benefits for girls (themselves possibly the cumulative outcome of higher opportunity costs as just described), the household is at a corner solution with respect to the girl's education: $\mathrm{S}_{\mathrm{G}}=0$.

The figure shows the effect of a gender neutral fall in cost, caused by a reduction in fees or other direct school costs. At lower marginal cost $\mathrm{MC}^{\prime}$, positive investments in girls' schooling become optimal and the household moves to $\mathrm{S}_{\mathrm{G}}^{\prime}$. The gain in girls' schooling is much larger than boys' because boys merely move incrementally along the continuous portion of the marginal benefits schedule. Similar results would obtain from a gender neutral improvement in the returns to schooling. Note that in this model, higher opportunity costs for girls not only can explain their lower mean levels of school attainment; they can also, via impacts on school continuation probabilities, explain gender differences in changes in schooling in response to policies. This is in contrast to the second example above which relied on additional assumptions about the shapes of the schooling cost functions for girls and boys.

An interesting aspect of each of the cases depicted is that they suggest a tendency for gender differences in response to policies affecting school price (and also quality) to be larger when the initial gender gap itself is large. In the example in Figure 5 of differences in dropout probabilities, girls are initially at a corner solution while the optimal schooling for boys is greater than completed primary, so the gender gap is large. Girls gain substantially relative to boys from the policy change by shifting up to the continuous segment of the benefits curve while boys just move along it. In contrast, if girls and boys both were initially on the continuous portion of the benefits curve the initial gap would be smaller, and gender neutral shifts in either marginal costs 
or benefits would have equivalent impacts on girls and boys rather than favoring girls. This logic would apply to quality improvements as well, since as discussed below such improvements can be interpreted as upward shifts in the schooling benefits curves.

Similarly, in the situation depicted in Figure 3, there is a large initial schooling gap because girls and boys are on different segments of the benefits schedule, and the effect of a rise in benefits or fall in costs is larger for girls because it causes them to move to the higher (postprimary) segment. For initial positions in which both girls and boys are on the same portion of the benefits curve, hence where there are relatively small initial gender differences, the same shifts in benefits or costs lead to similar impacts for girls and boys. It is easy to demonstrate that the cases in Figures 1 and 2, of boys' marginal benefits falling faster than girls' or boys' marginal costs rising faster than girls', also imply an association of large initial gender gaps and stronger policy impacts for girls. Also as discussed below, the model assumptions behind Figures 1 and 2 in particular lead to the prediction that increases in household resources will have larger effects on girls' schooling than boys', consistent with findings from a large number of empirical studies.

\section{Evidence for Impacts of Policies on Girls' and Boys' Schooling}

\subsection{Introduction}

With the theoretical discussion providing a general framework for interpretation, I turn to the evidence, following a brief discussion of methodological concerns. The evidence comes, as indicated, primarily from econometric analyses of schooling demand and a smaller number of policy experiments. By and large I do not delve into the large body of less formal assessments of gender-focused interventions, since few of these have been statistical or rigorous enough to permit reliable inferences (few, for example, collect baseline information; see Kane 2004 for a review). The most common outcome variable considered in empirical work is current enrollment, though a number of studies also consider grade attainment or dropout/continuation. Enrollment information is readily available in household surveys and not subject to sample selection or censoring, but it is a rather imperfect measure of human capital. It does not capture ultimate schooling attainment, and it (like attainment) does not directly measure cognitive skills.

I also refer below to a few studies that do consider effects of school factors on girls' and boy's skill acquisition (measured by test scores). These remain rare for developing countries, and have their own shortcomings, notably potential selectivity bias since they almost always involve in-school samples without corrections for selection into this sample. Where gender gaps in enrollment or dropout are large, selection may operate more strongly for girls, rendering gender comparisons of learning determinants problematic.

\subsection{Methodological issues}

Studies attempting to discern the casual impacts of school characteristics or education interventions using non-experimental data face a number of potentially significant problems. These include measurement error in school characteristics, omitted variable biases, and biases 
due to heterogeneity in unobserved community or household characteristics (themselves a form of omitted variable bias). Omitted variable bias in regression can arise from the exclusion of education inputs, costs, or other factors that are correlated with the levels of the included attributes and also affect learning or education outcomes. The school facility surveys or community surveys with school data that accompany household surveys tend to be fairly limited, so incomplete school input information is a common problem. If levels of omitted and included school inputs are positively correlated, the estimated effects of the latter on education demand will be biased upward. Even when school data are more comprehensive, unobserved heterogeneity at the community or household level can bias estimates of school quality effects. Communities where education is valued will be those where parents would tend both to keep their children in school and insure that local schools have more resources; also, households with strong education preferences may move to areas where school quality is higher. In contrast, if governments seek to locate facilities or upgrade quality where the demand for education is weak, there would be a downward bias in the estimates of the effects of school quality on demand.

The traps of unobservable heterogeneity and endogenous program placement are in principle avoided in policy experiments in which some individuals (or communities, or schools) are randomly selected to receive an intervention and others are not. This approach has for good reason been increasingly advocated and used in developing country policy research, and several studies below describe education policy experiments with gender as a focus. If the randomization is valid the experiment provides an unbiased estimate of program impact on the study population. Still, experiments can be difficult to implement for logistical or cost reasons. They also have their own limitations, in particular in regards to external validity, that is, the generalizability of results from the study population, which is often small or confined to a specific geographic area, to the overall population.

Among the far more numerous analyses that use non-experimental data, most simply assume that school factors are exogenous. In view of the potential problems just noted, findings in such cases need to be interpreted with care. In some studies, researchers do adopt one or another approach to deal with selectivity or endogeneity. For the evaluation of specific interventions these include most prominently propensity score matching, which compares individuals or groups receiving an intervention with others that are similar in terms of observed factors. Difference in difference techniques are sometimes used as well; this method compares changes in outcomes for intervention and comparison groups, thereby controlling for factors that cause baseline levels of the outcomes to differ. The reliability of these approaches has been the subject of investigation and debate: recent assessments suggest they can produce valid causal inferences in some circumstances (with certain kinds of data or policy rules) but not others (Glazerman et al. 2003; Cook et al. 2006). A more traditional approach among economists to identification with non-experimental data is the use of instrumental variable techniques. However, there are few examples of IV methods in the studies discussed below, primarily because convincing instruments for school characteristics (variables that affect these characteristics but have no direct impacts on outcomes) are typically very hard to find. In the conclusion of this paper I return to the discussion of methodological approaches.

It should be pointed out that while heterogeneity and omitted variables can lead to biases in non-experimental estimates of the effects of school characteristics on education outcomes, the 
implications are less clear with respect to estimates of the difference in effects for boys and girls, which is of primary interest here. In particular, if omitted factors have equivalent effects on girls' and boys' schooling outcomes they will lead to similar upward or downward biases in the estimates for included regressors, and these will be eliminated from the difference in the girl and boy estimates. ${ }^{13}$ Note, however, that the assumption of equivalent effects of unobservables may be strong, particularly given that the analysis is predicated on the possibility that the factors that we do measure affect the genders differently. If it is violated, there will be differential bias in the level estimates for girls and boys, and hence also a bias in the observed difference in the girl and boy effects.

Essentially the same idea motivates the use of household fixed effects techniques to test for male-female differences in the effects of regressors. Here the assumption is that household level unobservables (including education preferences and motivation, home inputs into learning, and ability) influence the levels of the outcomes for both girls and boys but that this effect does not differ systematically for girls and boys. Therefore differencing across gender within the household - estimating the boy-girl difference in outcomes rather than the level for each gender-isolates the true gender differential in the effect of the variable. Here too the implied restrictions may be strong. One would have to assume, for example, that parents with strong preferences for human capital and who therefore may provide more home inputs into learning or move to areas where school quality is high do not also have relatively strong preferences for educating girls. ${ }^{14}$ Still, this approach seems like a logical way to analyze gender differences in the effects of school (and other) factors affecting education outcomes. Despite this, in the literature considered in this review the use of household fixed effects or within family estimators remains rare; Pitt and Rosenzweig (1990) is the only such study of which I am aware that uses the approach to investigate differences by gender in the effects of a variable on schooling outcomes (infant sibling's illness in their case, not school characteristics).

One other prefatory note on methodology is called for. There is considerable variation in how researchers compare the effects of covariates across gender. These comparisons should always be statistical. The fact that more often than not the models are nonlinear adds some complications for constructing the correct tests, though usually not major ones. For example, for probits for current enrollment, the appropriate comparative statics are the marginal effects, i.e., the change in the probability of enrollment for a unit change in the variable, and it is these which should be compared statistically (see Glick, Saha, and Younger 2004 Appendix 2.2 for detailed discussion).

\footnotetext{
${ }^{13}$ In standard omitted variable formulae, the bias in the estimated coefficients take the form of an additive term; if this level bias is the same for girls and boys, it drops out of the difference in the estimates. For measurement error, on the other hand, the bias takes the form (in the textbook case of a variable with random measurement error) of a proportional reduction relative to the true parameter. This means that the difference in the girls' and boys' estimates will be proportionately underestimated even though the (proportional) degree of measurement error bias is the same for both.

${ }^{14}$ It follows that fixed effects or within family estimators will be less reliable for assessing gender differences in effects of programs or inputs designed specifically to target girls' schooling than for policies that are ostensibly gender neutral. Families living in communities with schools that have explicit pro-girl education policies may be those with strong preferences for girls' human capital relative to boys'.
} 
In practice, girl-boy effect comparisons in the literature tend to be somewhat casual. One common practice is to infer that a gender difference exists if a variable has a significant impact on an outcome for one gender but not the other. For example, school cost may have a significant negative effect on girls' enrollment but not boys'. However, these two results together do not support the statement "girls" enrollment is more sensitive to cost than boys"". Given that we are dealing with probability statements, this can only be concluded based on direct statistical comparison of the impacts on girls and boys. It is entirely possible for there to be no significant difference in these impacts despite having one impact significantly different from zero and the other not. Nevertheless, my review of the demand literature adopts a liberal approach and includes results of the kind just described, both because these types of 'casual' comparisons are common and because otherwise the literature comparing gender impacts would become rather sparse.

\subsection{Effects of household resources}

Now I turn to evidence for the effects of various policies on girls' and boy's schooling. 'Household resources' may not seem to be a logical starting point for this discussion. Policies affecting incomes are not 'education policies' per se; they affect schooling outcomes only indirectly by changing the level of resources of the household. Nevertheless, household wealth or income is almost always a powerful predictor of child schooling investments, so research that investigates whether these effects differ by gender is of significant interest. The issue is also of interest because of similarities in the way the conceptual framework presented above can be used to explain differential responses to changes in resources, on the one hand, and changes in school cost and quality on the other.

It is common for researchers to report higher income impacts on enrollment or grade attainment for girls. The settings where this has been reported are diverse: India (Sipahimilani 1999, Basu 1997), Malaysia (de Tray 1988), Peru (Ilahi 1999), Mexico (Parker and Pederzini 2001), Turkey (Tansel 2002), Tanzania (Mason and Khandker 1996), and in West Africa, Guinea (Glick and Sahn 2000) and Senegal (Glick and Sahn 2005a). Schultz (1985) comes up with a similar pattern using national level time series data for some 90 countries over two decades, with gender specific enrollment ratios as outcome measures. The boy-girl differences vary considerably across the studies just enumerated but are often substantial: it is common to find coefficients on household income that are twice as large for girls as for boys. The larger income elasticities for girls in these contexts imply that the gender gap narrows with income: boys become less favored. Based on this evidence from demand studies (as well as a number of descriptive analysis of schooling gender gaps by income quantile, see Glick, Younger and Saha 2004 for a review), stronger income impacts on girls' education is sometimes treated as if it were an empirical regularity (see e.g., World Bank 2001).

However, other education demand studies do not find gender differences in income or wealth effects (Shapiro and Tambashe 2001 for Kinshasa, Congo; Glick, Saha, and Younger 2004 for Uganda and Madagascar). In a few cases researchers have found larger effects for boys, though this appears to be far less common than examples of larger benefits to girls. Alderman et al. (1997) for rural Pakistan and Bouis et al. (1998) for the Philippines both report significant impacts of household resources on boys' schooling outcomes but not girls'. Tansel (1997), 
looking at primary, middle, and post-middle schooling determinants in Côte d'Ivoire and Ghana, finds that, by and large, per adult household expenditures affects only girls' schooling in the former but only boys' schooling in the latter.

Therefore while many empirical studies find stronger income impacts on girls' education, this is by no means a universal pattern. Is this because the existence of gender differentials in the impact of household resources depends on the size (or presence) of the initial gender schooling gap, which varies greatly across these samples? In the multivariate studies just discussed, it is hard to discern any such pattern. For example, increases in household resources benefit girls' schooling more than boys' both in Guinea, where there is a large pro-male enrollment gap, and Peru, where there is not.

Further evidence on this issue comes from Filmer's (1999) study using comparable Demographic and Health Surveys (DHSs) from 41 developing countries. Estimating probit models of enrollment for children age 6-14 that interact gender with a household wealth index, Filmer reports significant gender-wealth interactions in slightly less than half (18) of the countries - but these cases are exactly equally divided between those showing higher wealth benefits for girls' schooling than boys' and those showing the opposite pattern. ${ }^{15}$ However, closer examination shows that the countries where increases in wealth more strongly favored female enrollments also tended to have sizable average pro-male enrollment gaps, while most (7 of 9) of the countries where increasing resources brought stronger benefits to boys' enrollments had either no average gender gap or very small gaps in favor of one gender or the other. Therefore there is something of a pattern in these regressions using internationally comparable data.

However, to say that where one finds increases in wealth or income benefiting girls' schooling more than boys' one is also likely to see a large average pro-male schooling gap is not the same as saying that wherever such gaps exist, increases in resources will favor girls. Indeed, many of the DHS countries with large average gaps favoring boys exhibit no significant interactions of wealth and gender in Filmer's regressions. Therefore both this multi-country econometric analysis and the totality of the country examples discussed previously do not support either a general claim that increases in household resources will favor girls' education investments over boys' or the narrower claim that this will happen when boys initially are strongly favored. The evidence does suggest that pro-girl outcomes tend to occur more in contexts where the average or initial gender gap favoring boys is large.

Even if they are not always found, larger impacts of household resources on girls' education nonetheless are frequently seen. Why would this occur? Two explanations arise from a consumption perspective, i.e., one based on parental preferences. Parents may view girls' education and health as more of a luxury good than boys', implying a higher income elasticity for the former. Or, 'inequality aversion' may be a normal good: at low incomes parents invest more in the human capital of boys if the labor market returns are higher for male schooling, but at higher incomes they increasingly allocate resources to girls as well because their desire for fairness in allocations increases (see Garg and Morduch 1996).

\footnotetext{
${ }^{15}$ See Filmer (1999), Table 8.
} 
In their discussion of health investments in children, Garg and Morduch offer an alternative explanation based on a human capital investment model, under the assumption of higher concave total returns to boy's human capital than girls' (and thus more rapidly declining marginal returns for boys). This case for education was depicted above in Figure 1. Poorer households lack access to credit markets to fund education investments, and thus are constrained by the level of current household resources. A simple way to portray this is to assume that rather than being able to invest optimally until the net marginal return (marginal benefits minus marginal costs) equals zero for both the daughter and son (occurring at $S_{B}$ and $S_{G}$ in Fig. 1), the household can only purchase some lower total amount of schooling for the son and daughter. ${ }^{16}$ The household still allocates its investment budget so that the net marginal benefits are equal for the two, but this now occurs at some positive value. Given higher marginal benefits for boys than girls but equal marginal costs, this will always involve higher schooling for boys. An expansion of the total education budget as household resources increase means that equality of male and female net marginal benefits will be achieved at higher levels of $\mathrm{S}_{\mathrm{B}}$ and $\mathrm{S}_{\mathrm{G}}$. Since marginal benefits, hence net marginal returns, are falling more slowly in years of schooling for girls, reaching the same (lower) value for net marginal returns for girls and boys implies a larger increase in girls' schooling.

A similar result would occur under the conditions depicted in Figure 2. In this case, marginal costs are higher for girls so their initial schooling is lower. But since girls' marginal costs are rising more slowly than boys', net marginal returns again are falling more slowly for them than for boys, hence an increase in household resources for education leads to a larger change in schooling for girls.

\subsection{Effects of price/distance}

\section{Evidence from demand studies}

Considering now the impacts of school factors, we begin with costs. School cost is represented rather broadly in the empirical literature: in some cases it is measured by price (school fees or fees plus other obligatory expenditures) but in many or even most developing country studies it is proxied by the distance to, or just the presence of, a facility. Since in many countries public education is nominally free, distance to schools is frequently the only costrelated variable available in surveys. Distance is associated both with direct costs for transportation and with opportunity costs: more time spent traveling to and from school implies greater foregone income or output from a child's home, farm, or other productive labor. In some cases opportunity costs are expressed in monetary terms. To do this, the time spent traveling to school plus the estimated hours in school are multiplied by the relevant local wage or the individual's predicted hourly value of time based on an earnings regression. ${ }^{17}$ When using school

\footnotetext{
${ }^{16}$ A more accurate way to depict this, but leading to the same outcome, would be to have marginal costs rising in years of schooling for credit constrained households. This can occur if the cost of borrowing rises with the amount of schooling, or (for a fully constrained household that must finance schooling completely out of income) because the marginal value of foregone current consumption increases as schooling rises and current consumption falls.

${ }^{17}$ While this procedure is attractive conceptually, the use of wages to represent the opportunity cost of time is problematic in most environments because typically few children participate in wage labor. Even where such
} 
fees as a cost measure, non-experimental studies with limited information on school characteristics may be subject to serious omitted variable biases. If schools where tuition or other costs are high are also of higher quality (which would tend to increase demand), estimated price effects may understate the negative impact of cost on demand.

Many non-experimental studies using household survey data find that girls' schooling is more sensitive to cost, however defined, than boys' ${ }^{18}$ Distance to school or the absence of a nearby school has stronger negative impacts on female than male enrollments in settings as varied as India (Sipahimalani 1999), Ghana (Lavy 1996, Tansel 1997), Senegal (Glick and Sahn 2005a), Malaysia (DeTray 1988), the Philippines (King and Lillard 1987), and Pakistan (Hazarika 2001; Lloyd et. al. 2005). ${ }^{19}$ In Kenya, higher school fees increase dropout probabilities for girls but have no effect on boys (Lloyd et. al. 2000). In rural Pakistan, girls' enrollment but not boys' is sensitive to direct costs (Lloyd et. al. 2005). Schultz's (1985) study provides evidence from cross-country aggregate data. Using public education expenditures per teacher as a measure of the price of schooling, he finds greater price responsiveness of girls' education, measured by enrollment ratios. Note that for this result to reflect actual demand behavior by households as in studies on micro data, one must assume that higher public expenditures for teachers translates into higher school costs to households. ${ }^{20}$

This is an impressive array of cases, but Filmer's (1999) comprehensive analysis of comparable Demographic and Health Surveys cautions (again) against making general claims about gender differences in impacts. Filmer includes indicators for the presence in the community of primary or secondary schools in probits for current enrollment for 19 countries. Better physical access usually strongly encourages school enrollment of rural children 6 to 14 ,

estimates can be obtained, their reliability is unclear. On the one hand, average wages or wages predicted from regressions may underestimate an individual's true value of time, since the decision not to enter the wage labor market may be due to marginal productivity in family firm or household activities being higher than the offered market wage. On the other hand, child wage labor may be rare because this market is highly imperfect: many parents are presumably unwilling to allow their children to work outside the home or family enterprise. In this case the market wage could be significantly higher than the child's marginal productivity of labor at home. Another approach to representing a child's cost of time is to apply some fixed proportion of the local adult wage, but this is clearly an ad hoc solution.

${ }^{18}$ As indicated (note 9), most studies report, and make gender comparisons of, absolute rather than proportional changes in school outcomes. References in the text to the degree of 'sensitivity' or 'responsiveness' to a policy variable should be understood in this light.

${ }^{19}$ The reference here is to Hazarka's finding that girls' primary enrollment probabilities, but not boys', are negatively affected by distance. He also reports that the distance to middle school has a negative (marginally significant) impact on boys' primary enrollment but not on girls'. However, since few girls go on to middle school in rural Pakistan, the effect of distance to middle schools may not be relevant for girls or may simply be difficult to capture in the regression.

${ }^{20}$ It should be noted that, especially for studies using monetary cost measures, reported gender differences in the effect of school cost may reflect in part differing income elasticities for girls' and boys' education. This is because the reported price effects are usually uncompensated, that is, they include the income effects accompanying a price change. Estimates of the effect of distance similarly incorporate an income effect, since a reduction in time to school raises full income in the Beckerian sense. Studies using monetary measures of cost could easily net out the income effects if the model also included an income term, but this has generally not been done. 
but in only four cases is there a significant difference by gender in this impact (three showing a stronger effect for girls). Similarly, Glick, Saha, and Younger (2004) for Madagascar and Tansel (1997) for Cote d'Ivoire find statistically equivalent distance effects for girls and boys.

Still, in many cases girls' schooling is found to respond more strongly than boys' to changes in school distance or availability, while the opposite is very rarely found. How appropriate is it to interpret the former result as indicating that girls' schooling is 'more pricesensitive'? Although this interpretation is often made, it may not be valid. Responses to changes in travel time or distance to schools might differ by gender even if the impacts of a change in monetary costs, e.g., a fee reduction, would not. Parents may be reluctant to allow girls to walk long distances to school on their own, in which case sending daughters to school may entail transportation costs, or else psychological costs, that are not incurred for sons. Having a school close by thus may reduce the effective costs of girls' school attendance while having no effect or a smaller effect on costs for boys.

This can happen as well if the value of daughters' time is higher than sons', due say to a strong demand for daughters' work in the home. The effect of an increase in distance is to raise the marginal cost of schooling for girls and boys via a reduction in the time available for work, hence in current consumption (and possibly, future parental consumption via declines in child work experience). Although the reduction in potential work hours is equivalent for girls and boys, if girls' shadow wage is higher, the value of foregone current output is larger, so all else equal girls' marginal cost rises more than boys'. ${ }^{21}$ Conversely, a decrease in distance would reduce marginal costs and increase schooling more for girls than boys. In contrast, a change in school fees would lead to equal shifts in marginal costs for girls and boys.

Whether or not the estimated effects of distance capture a standard price effect, findings showing stronger distance impacts on girls are highly policy relevant: they indicate that school construction programs that reduce the average distance between home and school can have disproportionate benefits for girls' education. They studies also imply that the process of urbanization, which generally brings households in closer proximity to public services such as schools, should also have larger relative effects for girl's education. ${ }^{22}$

\section{Evidence from program evaluations}

A different source of information on how investments in girls' and boys' human capital respond to costs are evaluations of interventions that attempted to improve schooling outcomes via price or other financial incentives. Several of these studies are based on randomized policy experiments, or else utilized "natural experiments". An example of the latter is Angrist et al.'s

\footnotetext{
${ }^{21}$ In eqs. (4a) and (4b), marginal school cost includes the term $\mathrm{P}+\mathrm{r}_{\mathrm{i}}\left(\partial \mathrm{Y}_{\mathrm{i}} / \partial \mathrm{L}_{\mathrm{i}}\right)\left(\partial \mathrm{L}_{\mathrm{i}} / \partial \mathrm{S}_{\mathrm{i}}\right)$. For an increase in travel time to school, the work time given up with additional schooling, $\partial \mathrm{L}_{\mathrm{i}} / \partial \mathrm{S}_{\mathrm{i}}$, is equal for girls and boys, but for girls it is multiplied by a higher shadow wage $\left(\partial \mathrm{Y}_{\mathrm{i}} / \partial \mathrm{L}_{\mathrm{i}}\right)$.

${ }^{22}$ Gender schooling gaps, especially at post-primary levels, do tend to be smaller in urban areas, though a variety of reasons in addition to greater accessibility are also at play, such as higher average incomes and parental education as well as exposure to modern attitudes and female role models in the mass media.
} 
(2002) study of Colombia's national voucher system for private secondary schooling, in which a limited supply of vouchers was assigned to qualified low income public primary students based on a lottery system (hence was randomly assigned). Eligible girls and boys were equally likely to receive the subsidy. Although voucher recipients of both sexes did modestly better in terms of school attainment and test scores, the effects were larger for girls.

In a rather different demand side intervention, Mexico's PROGRESA program, poor rural communities were randomly assigned to receive inducements for school enrollment in the form of education and food grants to mothers conditional on their children attending primary school and being brought in for regular medical checkups (Skoufias 2001). Estimates by Schultz (2004), consistent with previous evaluations, indicate overall enrollment impacts that were larger for girls: between 3.4 and 3.7 percentage points, depending on sample and method, compared with 2.5 to 2.8 for boys, with larger differences for secondary enrollment. ${ }^{23}$ In contrast, assessments of the school attendance impacts of other conditional cash transfer programs in Latin America, including in Nicaragua (Maluccio 2002), Ecuador (Araujo and Schady 2006), and Brazil (Cardoso and Souza 2003), show similar gains for boys and girls. Note, however, that unlike in Mexico, in each of these contexts girls were not initially disadvantaged or even (as in Ecuador) had somewhat higher enrollment than boys.

In Bangladesh, the Food for Education subsidy program offered households a monthly food ration conditional on a child's school attendance. In the initial two years of the program, enrollment in schools participating in FFE skyrocketed (though some of the measured increases may have reflected shifts from non-FFE schools) and the gains were much larger for girls than boys - $41 \%$ vs. $28 \%$ (Ahmed and del Ninno 2002). Unexpectedly given these figures, this pattern was not confirmed in an econometric analysis using household survey data carried out by Ravallion and Wodon (2000). Using village participation in the FFE program to predict the potentially endogenous household food ration, these authors report positive effects that were statistically similar for girls and boys. ${ }^{24}$

A very different source of evidence on the impacts of changes in direct costs is the recent experience of several countries in which primary school fees were eliminated or sharply reduced nationwide. In Uganda, Tanzania, and Malawi, such policies resulted in sudden and very large surges in enrollments, with girls' enrollments increasing the most (See Herz and Sperling 2004 and references therein). In one sense these major shifts in pricing policy can be viewed as natural experiments, though this interpretation is somewhat problematic, in part because the shift typically coincided with other policies such as publicity campaigns to promote schooling. Even taking such factors into account, however, these country experiences point to the presence of substantial price responsiveness of education demand, and especially for girls. Of course, where fee elimination actually comes close to achieving universal enrollment, as in Uganda in the late

\footnotetext{
${ }^{23}$ It should be noted that the subsidy was not completely gender neutral: there was a premium for girls starting at junior secondary school, but this was small (less than $10 \%$ except for the highest grade).

${ }^{24}$ However, since participation in FFE is contingent on enrolling a child, predicted program participation of the household, hence also the level of the food ration, must itself be partially a measure of school enrollment. Therefore the coefficient on predicted FFE participation in Ravallion and Wodon's enrollment probits is difficult to interpret.
} 
90s, it is inevitable that female enrollments will rise more if they were initially lower than male enrollments.

Nevertheless, these experiences, together with the evidence from both schooling subsidy programs and demand studies using monetary measures of cost, suggest that the demand for girls' schooling is often more price responsive than boys'- not merely more sensitive to distance. A framework in which schooling was viewed in consumption terms would explain differences in price elasticities with reference to parental preferences for girls' and boys' human capital. The human capital investment framework provides alternative plausible interpretations, several examples of which were shown in Section 2. The comparative static effect of a reduction in price will be larger for girls if, all else equal, marginal benefits fall less rapidly for girls than boys (as in Figure 1), the marginal costs rise less rapidly for girls (as in Figure 2), or under either of the two discontinuous returns scenarios of Figures 3 and 5.

When price effects are larger for girls, policies that reduce the direct costs to households of sending their children to school, even if they do not single out girls for special treatment, will disproportionately raise female enrollments or attainment. Such policies are appealing in that they achieve two important objectives, raising schooling overall while reducing gender gaps. Obviously, the converse is also true: cost recovery schemes that raise fees will hurt girls' enrollments more in these environments.

Finally, a potentially important question for policy is whether gender differences in responses to price differ for the poor and the non-poor. If girls are more sensitive than boys to an increase in costs and this difference is largest among poor households, cost-recovery policies will reduce utilization by girls more than by boys and by poor girls most of all. However, very few of the studies reviewed in this paper have investigated this issue.

\section{Targeted subsidies for girls’ schooling}

Education policies, of course, can also specifically target girls. Most would agree that where gender schooling disparities are large or persistent, targeting is warranted even if girls would benefit somewhat disproportionately from gender neutral policies. One approach operates on the demand side by lowering the costs to households of educating girls (i.e., shifting down the girls' marginal cost function in Fig 1 relative to boys'). Where this approach has been implemented, it has been effective at improving gender equity in schooling. An early example is the Bangladesh school stipend program, begun in 1982 to subsidize household expenditures on girls' secondary education. In the first five years of the program, girls' secondary enrollment rates in program areas rose from 27 to 44 percent, more than twice the increase observed nationally (Bellew and King 1993). Given this apparent success, the girls' stipend program was expanded in 1994. Khandker, Pitt and Fuwa (2003) estimate the impacts of the program using variation in duration of program exposure (caused by the staggered rollout of the expansion) combined with village fixed effects. They find that an additional year of availability of the stipend program increases girls' enrollment rate by 12 points while having no significant effect on boys'.

Filmer and Schady (2006) find similarly large impacts of a girls' lower secondary scholarship program in Cambodia (which actually was a conditional cash transfer to parents for 
enrolling daughters): OLS estimates show a 22 percentage point increase in female lower secondary enrollment, a result that proved robust to use of propensity score matching and regression discontinuity methods to deal with endogenous uptake of scholarships. Chaudhury and Parajuli (2006) use school level data to evaluate the impact of conditional cash transfers in Pakistan that also were targeted at lower secondary age girls. Estimates using difference in difference techniques combined with a regression discontinuity design indicate that female enrollment in stipend-eligible schools rose 9 percentage points. Estimates using repeated cross section household data (though potentially unrepresentative) suggest larger gains.

Kremer, Miguel, and Thornton (2004) report on a policy experiment in rural Kenya that combined demand and supply side incentives. Half of the schools in the study were randomly chosen to offer merit-based scholarships to girls scoring above a certain percentile on standardized examinations. In addition to this price incentive to households, schools had an incentive to improve girl's attendance and performance, as the schools directly received a portion of the scholarships. Girl's attendance as well as test scores in intervention schools were significantly higher than in controls, as was teacher attendance. Further, both girls with low baseline test scores, who were unlikely to win the scholarships, and boys, who were not eligible, also had test score gains in intervention schools. This may have been due to peer effects of being in classrooms with girls who were motivated by the possibility of a scholarship and thus worked harder.

Two earlier randomized evaluations, both in Balochistan Province, Pakistan, considered pilot programs to improve girls' access to local schools in a region where girls were significantly disadvantaged. The Quetta Urban Fellowship program relied on supply side incentives: it encouraged NGOs to build new primary schools in poor neighborhoods by paying a subsidy to the school (not to families) for each girl enrolled. Enrollment growth of girls in the intervention neighborhoods was 33 percentage points higher than in control neighborhoods (Kim et. al. 1999). Enrollment increased slightly for boys as well. Kim et. al. suggest that the sharp increase in girls' enrollments was in part an outcome of reduced distances to schools that would accept them. The second pilot program, in rural areas of Balochistan, supported village organizations in setting up and operating separate private primary schools for girls staffed by female teachers. Enrollment of girls initially rose 22 percent in program areas relative to control areas, while also rising 13 percent for boys (Kim et al. 1998). Although this program proved unsustainable, the initial success here and in the urban program in attracting female students is noteworthy. This presumably had to do in part with characteristics of the new schools that made them culturally appropriate for girls (considered below), not just with changes in price or physical accessibility.

\subsection{Characteristics of schools and the learning environment}

This section encompasses standard measures of school quality - number and qualifications of teachers, availability of blackboards and textbooks, and so on - but in addition considers factors that may not normally be considered measures of service 'quality', such as the share of female teachers. In reviewing this evidence, I follow Lloyd et al.'s (2000) distinction between characteristics of the school environment that are the same for boys and girls but nonetheless may have gender-differentiated impacts on outcomes, on the one hand, and aspects 
of the school environment that are different for boys and girls, on the other. Generally, policies that change school characteristics of the first kind could be described as gender neutral, while policies that change aspects of schools or the school environment that are different for girls and boys are usually conceived of explicitly as means of improving girl's attainment or learning, i.e., are gender targeted. In what follows it is important to keep in mind the methodological caveats raised in Section 3.2, particularly regarding non-experimental analyses.

\section{Aspects of school quality/environment that are similar for girls and boys}

There is some empirical support for the idea that standard aspects of school quality have stronger impacts on girls' education than boys'. Both Khandker (1996) for Bangladesh and Lloyd et al. (2000) for Kenya find that increases in indicators of teacher quality raise girls' enrollments or reduce their dropout probabilities while having no effect on boys' schooling. In rural India, Dreze and Kingdon (2001) report that various measures of school quality have larger or more significant impacts on girls' primary enrollments than boys'; the most impressive difference is in the impact of providing mid-day meals in schools, which raises the female enrollment probability by 15 percentage points. ${ }^{25}$ King et al. (1999) find for Pakistan that meritbased grade promotions have greater impacts on girls' school continuation than boys' (though rather than differential school 'quality' effects this could reflect a selection process whereby only high achieving girl students tend to get promoted for merit). In rural Pakistan, Hazarika (2001) finds that while having a local school with a drinking water supply has similar effects on boys' and girls' primary enrollment, having blackboards in schools is positively associated only with girls' enrollments. In Egypt, girls' dropout during grades 6-8 is associated with poor school quality in a number of dimensions while there are few such associations for boys (Lloyd et. al. 2003).

A natural experiment in India analyzed by Chin (2005) also points to stronger impacts on girls of changes in school quality, represented in this case by an increase in teacher resources. Exogenous variation was provided by an intervention through which the government was to provide an additional teacher to all primary schools initially having just a single teacher. Chin establishes that an additional teacher increased girl's primary completion rate by 3-4 percentage points and literacy rates by 2-3 points. In contrast, there were no significant effects on boys.

For most of these studies it not clear why the demand for girl's schooling responded more than boys' to improvements in service quality that were apparently targeted equally to both. The possibility should be noted that schools that are of 'high quality' in terms of standard indicators may also feature better (more supportive) learning environments for girls. If so, part of the apparent gender differential in response to quality in non-experimental studies may be due to other, unmeasured aspects of schools that differ for boys and girls. Assuming this is not the case, one might surmise that school and teacher improvements somehow affect girls' ability to learn more than boys', thereby inducing parents to enroll girls or keep them in school. In terms of the model of Section 2, an improvement in school quality increases the marginal benefits of schooling, since the increment to human capital from an additional year of school is larger when quality is higher. This raises the optimal level of schooling, and more so for girls than boys if

\footnotetext{
${ }^{25}$ As these authors note, the free meal is a form of education subsidy. The stronger effect for girls therefore may be an indication of greater price responsiveness of the demand for girls' schooling.
} 
girls' learning is more responsive to the change in quality. Note, however, that with the exception of the India study by Chin, this process can only be inferred indirectly from the evidence since these analyses consider only enrollment outcomes, not academic outcomes, i.e., test scores. Moreover, it is not readily apparent why changes in quality should have stronger impacts on girls' learning. ${ }^{26}$

Alternative interpretations of girl-boy differences in schooling responses to quality that do not require differential learning effects are possible, based on gender differences in the schooling benefit or cost functions as outlined in Section 2. Define equivalence in learning impacts from improved quality as a situation where for any level of schooling $S_{i}$ total benefits increase by some fixed proportion that is the same for girls and boys. Although the benefits curves for girls and boys shift up equiproportionately, the adjustments in the optimal levels of schooling will also be functions of the slopes of, or presence of discontinuities in, the marginal benefit and cost functions. For example, in the quadratic schooling benefits case in Figure 1, marginal benefits are declining faster for boys than girls, so the change in schooling required to restore equality of marginal benefits and costs after equivalent shifts in girls' and boys' benefits curves will be smaller for boys: girls' schooling increases more. The same outcome could be generated by differences in the slopes of the male and female marginal cost functions and is exactly what is illustrated in Figure 2 by the equivalent upward shifts in girls' and boys' marginal benefits functions. Similarly, in the discontinuous returns cases depicted in Figures 3 and 5 , it can easily be seen that equivalent girl-boy shifts in benefits curves from education quality improvements would also tend to disproportionately raise girls' schooling, again without assuming any gender differences in impacts on learning.

Further, as discussed in Section 2, each of these models also predicts that stronger impacts of quality on girls' schooling will occur in situations where initial girl-boy disparities are large. This is consistent with the presence of substantial mean gender gaps in the populations analyzed by the each of the studies cited above. However, it should be kept in mind that the pattern in existing research may be an artifact of the choice of study environments; researchers may not have bothered to address this issue in cases where gender disparities in education were small.

\section{Aspects of school quality/environment that are different for girls and boys}

There is little doubt that in many countries the school learning environment favors boys over girls (World Bank 2001), for reasons that may include a lack of female teachers, unfavorable teacher treatment of girls in class, sexual harassment by male teachers or students, and curricula and textbooks that present favorable adult role models only for boys. To the extent that these factors hinder girls' ability to learn, they reduce parental incentives to invest in daughter's education by reducing the marginal benefits of their education relative to sons' (in addition potentially to prompting girls' own decisions to withdraw). There are relatively few

\footnotetext{
${ }^{26}$ If school and home inputs are substitutes in the production function for human capital, and girls receive lower levels of home inputs than boys, then the marginal product of additional school inputs will be higher for girls. However, it is more plausible to think of most home inputs (e.g., schoolwork supplies, homework assistance or study time) as complements to school inputs.
} 
econometric or experimental studies of these issues, but the limited evidence appears to confirm the potential for negative effects on girls' education.

Female teachers

The provision of female teachers is frequently cited as a means for encouraging girls' school enrollment and academic performance. Parents in some cultures may be unwilling to send their daughters to school unless they can be taught by a woman. Having female teachers could encourage parents to enroll daughters via beneficial impacts on girls' academic performance, which would occur if girls respond better to female teachers or if female teachers encourage them more. In line with either of these hypotheses, in Bangladesh, having female teachers in local schools was found to increase girls' enrollment probabilities (Khandker 1996). Similarly, in cross-country regressions for Africa, Mingat and Suchaut (1998) find that having more female teachers is associated with higher enrollments and lower dropout rates for girls. Consistent with the idea that having female teachers boosts girl's performance, a five-country African study by Michaelowa (2001) found that $5^{\text {th }}$ grade girls' knowledge gains are larger when they are taught by a woman, while boys' are larger when the teacher is a man.

It is possible, however, that the presence of female teachers is not exogenous to girls' education outcomes. Local communities or parents associations often hire teachers to supplement those provided by the government, and could choose to hire women if girls' academic success is considered a priority. If teachers tend to work in regions where they were raised, localities with stronger traditions of (and thus also current preferences for) female education will have a larger supply of educated women, hence of female teachers. Either situation implies that the association of the presence of female teachers and girls' educational success may not be causal or at least, may overstate the true causal relation. Therefore randomized program evaluations of interventions involving the placement of women teachers are of particular interest. In one such experiment, the rural Balochistan program mentioned above, villages were assisted in opening primary schools for girls staffed by female teachers. As indicated, there were very significant gains in female enrollments in these villages compared with non-program villages. Unfortunately, the design of this experiment does not make it possible to disentangle the effects of its various elements, e.g., female teachers, girls-only schools, strong parental involvement, and effective reductions in distance to the nearest suitable school.

This is also an issue to some extent with the results of the randomized program evaluation by Banerjee et. al. (2000) of a policy in India set up to add teachers to informal schools run by an NGO. The program hired a second, female (if possible) teacher for schools in the treatment group. The intervention both significantly reduced the days the school had to be closed (another program objective) and led to a doubling of girls' attendance, while having no effect on boys'. It is not clear if the strong benefits for girls came because the additional teachers were female, because 'availability' (days open) increased in informal schools that were acceptable to parents for girls, or because general school quality improved with the increase in 
the number of teachers. ${ }^{27}$ As with the Balochistan program, however, the results do point to a package of measures that may lead to large gains for girls.

As indicated, one benefit of having female teachers for girls may be that they are more supportive of girls. Two non-experimental studies, using separate data sources from Kenya, examined the impact of teacher attitudes directly and suggest that they matter for girls' success. Lloyd et al. (2000) report that girls' dropout probabilities in Kenya are significantly influenced by teacher attitudes about whether math is important for girls, by differences in the (selfperceived) abilities of girls and boys to seek advice from a school staff member, and by differences (again, self-perceived) in the treatment of boy and girl students. Appleton (1995) finds that girls' exam performance, unlike boys', is negatively affected by unfavorable teacher evaluations of their abilities.

Separate toilet facilities for girls

Focus group analyses in a number of settings have indicated the importance for parents of having separate school toilets or latrines for their daughters, especially once they reach puberty (See Herz and Sperling 2004). In the Bangladesh study cited above Khandker found that having separate toilet facilities for boys and girls increased girls' enrollment probabilities and grade attainment. In Guinea, West Africa, construction of separate girls' and boys' latrines was a significant component of a major reform program for increasing both female and overall school enrollment in the 1990s. Both girls' and boys' enrollments rose dramatically over the period 1989 to 1997, but the female gains were much larger: gross enrollment for girls more than doubled (from a low base; see USAID 1999).

As in other cases, it is difficult to identify the specific effects of the policy of interest, because several other gender targeted measures were adopted as part of the Guinea education program, including increases in the number of female teachers and provision of special assistance to pregnant students. Still, the provision of separate toilets or latrines for girls is one intervention (and a relatively inexpensive one) for which the existing qualitative evidence of potential benefits seems very compelling.

Pregnancy and girls' dropout

One of the other measures featured in the Guinea program was assistance to pregnant students, which addresses a different problem that also clearly impinges more on girls. Girls typically withdraw from school if they become pregnant or marry; in the case of pregnancy this is usually required by school policy. The share of female dropouts that is due to pregnancy (or early marriage) is difficult to assess. Simple associations of the timing of pregnancy and school leaving do not indicate causality, since both outcomes (other than pregnancy resulting from harassment or rape) are endogenous variables that may be caused by the same factors. These can include lifestyle preferences for career as opposed to early motherhood, or an unencouraging

\footnotetext{
${ }^{27}$ However, the authors note that the effect on girls of adding a second woman was smaller when the first teacher is also female. This is consistent with a specific 'female teacher' effect where it is most important to have at least one female teacher to serve, for example, as a role model or counselor to girls.
} 
school environment for girls that makes them more willing to engage in behaviors that threaten school continuation. Asking respondents why they left school, as some surveys do, does not get around this problem. Rather than being the true cause, pregnancy could be cited as an ex post justification for leaving school. Either approach would likely lead to an overestimate of the effect of unplanned pregnancy on school withdrawal.

Among studies that have considered this issue, the findings of Lloyd and Mensch (2006) are noteworthy. Their study uses special DHS data for five francophone African countries with both retrospective information on timing of pregnancy and dropout and self reports on reasons for dropout. In four of the five cases, pregnancy was potentially responsible for only a small share of adolescent female school exits using either measure. These results cast doubt on the importance of unintended pregnancy as a reason for girls' dropout (all the more so given that they may be biased upward), at least in these contexts. Decisions of young women (or their families) to marry early are likely to be more important. But these decisions are much more likely to be jointly determined with schooling choices: families placing a low value on girls' education, or a high value on traditional patterns of early marriage and childbearing for daughters, will plan both on limited schooling and early marriage for their daughters.

In any event, constraints due both to early pregnancy or marriage are likely to increase in importance in regions such as Africa as efforts are made to keep girls in school longer, hence further into childbearing age. There is little evidence on what policies can effectively deal with dropouts from early childbearing, though these presumably would include assistance to girls to help them return to school after childbirth. More fundamental are sexual education programs to prevent early pregnancies and related interventions to inform adolescents on how to avoid HIV/AIDS. A number of mostly non-experimental studies of the latter yield mixed findings for behavioral impacts, including pregnancy (Gallant and Tyndale 2004). However, a noteworthy recent randomized evaluation in Kenya (Dupas 2006) found that teaching $8^{\text {th }}$ grade girls about the high HIV risk from older men led not just to a very large drop in the subsequent incidence of pregnancies by adult partners, but also a nearly one third overall decline in pregnancies.

Before moving on to policies outside the education sector, it should be pointed out very few of the regression studies discussed in this section interact provider characteristics with measures of household resources to see if poor households are more or less responsive than the non-poor to changes in the attributes of schools. There has evidently been much less concern about this issue than about how price elasticities vary across income groups. It follows that the more refined distinction of looking at whether gender differences in response to quality vary by level of income has not been addressed either. It would be of particular interest to see if aspects of service delivery that are purposefully designed to increase girls' participation - for example, providing female teachers in primary schools - have stronger effects on enrollments of girls from poor families than from non-poor ones. In sum, the existing demand literature is not informative about the interactions of gender and income in determining the response to changes in cost or (even more so) in the characteristics of schools. Yet this information could be of value for designing policies to close the gaps in access to schooling that exist between poor and non-poor, and between girls and boys. 


\subsection{Policies that address the opportunity costs of educating girls}

Girls in the developing world typically spend far more time than boys in domestic work. The idea that girls' access to education is constrained by their household work obligations is supported both by ethnographic studies (Nieves 1981; Safilios-Rothchild 1980; Engle et. al. 1985) and econometric demand analyses (Glick and Sahn 2000; Deolalikar 1998; Levison and Moe 1998; Pitt and Rosenzweig 1990). The latter show girls' schooling to be more negatively affected than boys' (if boys' is affected at all) by the presence of younger siblings, or in the case of Pitt and Rosenzweig, by the illness of an infant sibling. It is clear that households do not consider the time of girls and boys to be close substitutes in home production activities, a factor that obviously has more to do with culture and tradition than technological aspects of production. ${ }^{28}$

Given this pattern of child labor specialization by gender, policies such as subsidized childcare services that reduce the household's domestic work burden may in effect target girls' education, by reducing the demand for their labor at home and thus the opportunity costs of their attending school (and of doing schoolwork if they attend). The research just cited suggests inferentially that the benefits to girls of subsidized childcare may be substantial. Unfortunately, while there are anecdotal accounts of community-based childcare services freeing up girls' time for school attendance (see Herz and Sperling 2004), there have been few rigorous assessments. Still, one careful study for Kenya (Lokshin et. al. 2004) found that lower local childcare center costs increase both maternal employment and girls' schooling, while having no effect on boys.

Girls may also benefit from flexibility in school schedules that help them balance school and domestic responsibilities. Flexibility could be provided by holding afternoon sessions for girls, or opening small satellite schools to be nearer to where girls (and for that matter, boys) live and work. Often it is informal or community schools that offer these options. Although here too there is a lack of formal evaluations, descriptions of a number of such interventions suggest that they can significantly raise the school attendance of girls (Herz and Sperling 2004 and Herz et. al. 1991 discuss several examples). In some contexts (e.g., Pakistan's Balochistan Province, see World Bank 1996) offering later sessions for girls can address a different, cultural barrier to their education: double sessions make it possible for girls to attend school separately from boys.

A number of other policies, though generally more gradual with respect to their implementation and effects, will also serve to reduce the overall burden to the family of household work and in so doing should increase girls' ability to attend school. These include infrastructure investments that provide electricity (making cooking more convenient and allowing refrigeration, thereby reducing the frequency of shopping) and convenient access to clean water (reducing the time needed for water collection, washing and food preparation). They include as well family planning services that lead to reductions in fertility, since fewer siblings mean a smaller burden of childcare on older sisters. Note that some of these time savings are likely be used to 'finance' increased activity of adult women in the labor market rather than just

\footnotetext{
${ }^{28}$ This may involve more than just culturally determined preferences of parents regarding the proper roles of girls and women. For example, discrimination may make labor market prospects unfavorable for girls. If, as a result, girls are, as adults, likely to spend more time in domestic work than market work, it may make sense to parents that they accumulate experience in non-market production rather than continue in school.
} 
their daughters' time in school. As discussed below in Section 3.9, however, an increase in female participation in the labor force may itself raise the household's perceived returns to investing in girls' education.

\subsection{Public information campaigns to encourage girls' schooling}

Where traditional beliefs make parents reluctant to send daughters to school, there may be an important role for programs using various media to promote the benefits of educating girls. For poorly educated parents in particular, such campaigns may be justified on efficiency grounds. They can supply information that these parents may lack on the benefits to female schooling, for example, improved child nutrition. Because parents lack complete knowledge of the benefits, female schooling would otherwise be undersupplied from a social point of view. Such 'sensitization' interventions are attractive as well because they are inexpensive compared with, say, scaled up improvements in teacher training or textbook availability.

It is difficult to assess the effectiveness of such campaigns. For one thing, they tend to be implemented in conjunction with other education policies (nation-wide or local), making it hard to attribute enrollment gains specifically to the outreach efforts. For example, in the case of Uganda's universal primary enrollment strategy of the late 1990s, promotion of school enrollment through the media was an accompaniment to more dramatic policy changes, notably the elimination of primary school fees. Community-level policy experiments to assess the efficacy of mobilization programs are a possibility. Under such a design the programs would be carried out in some communities and not others. This experiment would still only be able to evaluate locally implemented programs, so it would not be informative about other potentially effective ways the government can spread information, i.e., through national level mass media such as radio or television.

In any event, claims have been made for the effectiveness of community based efforts to sensitize parents to the need to school their daughters. For example, both Kane (2004) MillerGrandvaux and Yoder (2002) note a number of African projects in which community education campaigns, often in the context of programs to initiate new community (i.e., informal) schools, were associated with large gains in female enrollment or at least more gender equity than in existing public schools. However, here too it is not clear how important sensitization was in most cases given that other changes, such as a move toward flexible schedules, may have also induced more parents to enroll girls.

Discussions of such community information efforts also often emphasize the role of community 'participation' or active involvement in initiatives to raise girl's schooling. It is argued that this is an important determinant of program success (see Kane 2004). Rigorous evaluations of impacts are lacking. Barriers to such assessments include not just the presence of other policies associated with the female schooling initiatives, but the possibility that communities where participation in these initiatives is strong may be those where female education is relatively highly valued, or where women have a more prominent role in community decision making. These factors may lead to high rates of girls' enrollments even without the program. In principle, community level evaluations could be used to estimate the impacts of programs created to encourage local participation in girls' education. 
More broadly, the concept of community participation is often linked to the idea of decentralization of control over school management and supervision, a movement that has gained currency as a result of the serious inefficiencies and mishandling of resources seen within many centralized school systems. Several community level experiments have recently been initiated to assess the impacts of providing communities with greater decision making power or else more capability to monitor school officials (See Glewwe and Kremer 2005 p. 45 for a brief description). These assessments apparently do not involve initiatives to raise girls' schooling, but a different and potentially important question is raised that such experiments could presumably address: does a transfer of power over schools from centralized authorities to local communities lead to greater, lesser, or unchanged gender equity in access to education? Or perhaps, to greater variation in gender equity, if communities are heterogeneous with respect either to preferences for equity or to women's power in local decision making?

\subsection{Addressing social exclusion and girls' education}

There is a strong correlation of low female education and membership in socially excluded groups such as ethnic and linguistic minorities (Lockheed and Lewis 2006). Girl-boy schooling disparities within socially excluded groups, for example indigenous Mayans in Guatemala and lower castes in India, are often much larger than in the majority population. This suggests that many girls suffer a double disadvantage, as members of excluded groups and as females.

It may be noted, however, the association of exclusion and low female schooling does not indicate that membership in socially excluded groups itself is the source of low schooling for girls. For example, such groups tend to be poorer and live in more remote areas with less access to schools. As seen above, distance to schools tends to constrain girls' schooling more than boys, and many studies similarly show that reduced household resources have a stronger negative impact on girls than boys.

In other ways, however, excluded group membership may constrain girls more directly. Having less contact than boys with the environment outside the home, girls are less likely to be comfortable in the dominant language, which is usually the only language of instruction in schools; cultures of excluded groups may be more conservative, creating particularly strong parental reluctance to keep girls to school; labor market discrimination against ethnic minorities may be more severe for women, reducing private returns to educating minority girls relative to boys. One or another of these factors is suggested by some multivariate analysis case studies such as for Guatemala (Hallman and Peracca, forthcoming) and Nepal (Stash and Hannum, 2001) where indigenous group or caste membership is associated with boy-girl differences even after controlling for wealth, location, and other factors.

To formulate appropriate policies, the reasons for low enrollments of girls in socially excluded groups need to be understood. For example, if remoteness (hence long distances to schools) rather than any cultural differences explain low schooling of girls in an ethnic minority, building more rural schools will help get them in school, as already noted in section 3.4. Other causes, however, imply more explicit policies to aid girls in excluded groups, for example, through instruction in minority languages or targeting conditional cash transfer programs to 
minority girls. Social exclusion is still a new focus of research on schooling and gender, and more evidence, including on the effectiveness of specific policies, is likely to emerge in the near future.

\subsection{Labor market policies}

\section{Implications of female and male patterns of labor market activity for returns to schooling}

The human capital investment model implies that household schooling decisions are influenced by, among other factors, expected returns in the labor market. Therefore policies that affect the operation of labor markets may have significant impacts on incentives for private investments in girls' and boys' education. There is little direct evidence on this issue from studies using micro data, reflecting inherent difficulties in arriving at the appropriate counterfactual. Labor market policies typically operate at the national level, so researchers lack within-country variation in policy variables or associated variation in female and male education returns to include in models of schooling demand. Given this relative dearth of micro level evidence, the discussion in this subsection will be somewhat more conceptually than empirically oriented. $^{29}$

To understand the implications for education demand of policies related to the labor market, it is necessary to understand the relationship between expected labor market outcomes and household schooling investments. This involves, naturally, the effect of additions to schooling on the pay of women and men, which has been the focus of many studies in developing and well as developed countries. But the returns to education for women are more complex than this, because their participation and labor supply is usually more variable than men's. Because of their roles in childrearing and other domestic production, women are more likely to experience temporary or permanent withdrawal from the labor force. They may be less likely to enter the labor force at all, or may work part-time rather than full time. In most societies, therefore, parents would be correct in anticipating that daughters on average will end up spending fewer years full-time in the labor force than will sons.

Even where additions to schooling raise hourly compensation equivalently for males and females, these differences in labor supply imply that investment in another year of education of a girl increases expected lifetime labor market earnings (or average yearly earnings) by less than it would for a boy. The difference, in proportional terms, is essentially equal to the share of predicted full time equivalent years of labor force participation of a woman relative to that of a man. The effect of this on the anticipated benefits to investments in a girl's education relative to a boy's will depend on (1) the effects of schooling on labor productivity in non-market compared with market (i.e., labor force) activities, (2) the extent to which parents are aware of these productivity effects, and particularly if they are aware of the non-market benefits, and (3) the

\footnotetext{
${ }^{29}$ Labor markets, especially in agriculture, can often be characterized as local rather than national, providing spatial variation in female and male wages that might be used to estimate the effects of female and male potential earnings on enrollments of girls and boys. However, it is unlikely that schooling decisions would be affected only by what is observed in such local markets, because schooling provides options for remunerative non-agricultural employment and it may be anticipated that educated children (perhaps sons more than daughters) will migrate to urban centers for work.
} 
value parents place on these future non-market benefits relative to the daughter's market production.

The fact that typically during certain periods of their lives women allocate more time to home than market activities suggests that the marginal productivity of their time in the formerparticularly in child rearing - is higher than the market wage during such periods. This does not, however, say anything about whether the effects of schooling on productivity are higher in market or non-market work. There is, to be sure, abundant evidence of the positive impact of women's schooling on non-market productivity, particularly as measured by child survival and nutritional status (Schultz 2002). However, these effects have not usually been directly compared with estimated returns to schooling in the labor market for the same population, so it is hard to answer question (1); this would be difficult to do, since all benefits would have to be assigned the same, e.g. a monetary, metric. In fact, for understanding household investment decisions the relevant metric would be parental valuations of these future non-market outcomes, in particular, nutrition and other aspects of the welfare of their daughter's children.

About these valuations (question 3) little is really known. Most researchers would consider it rather unrealistic to assume that parents fully internalize the welfare of the generation following the next one (i.e., their grandchildren) when deciding about educating their sons and daughters. This view is implicit in the near universal labeling - at least by economists — of the effects of female schooling on children's well being, including children's health and schooling, as 'externalities'. With reference to (2), in many contexts it is also likely that parents are not fully aware of the non-market productivity gains associated with female schooling. While there is little direct evidence of which I am aware on this issue, these considerations make it reasonable to assume that in parental decision-making about human capital investments of girls and boys, the effect of schooling on productivity in non-market activities carries less weight than its impacts on income. Therefore the smaller increase in expected annual and lifetime labor market earnings from additional schooling for a girl than a boy implies, all else equal, that the expected household benefits at the margin to educating daughters will be lower than for sons.

'All else' is not necessarily equal, however. The foregoing conclusion, which is based on differences in average lifetime labor force behavior of males and females, ignores the fact that schooling itself may strongly influence patterns of female participation and labor supply, hence lifetime incomes. For both genders, there will be a negative 'base' effect of schooling on total years in labor force because age at labor force entry is higher for those who stay in school longer; indeed adult male labor force participation in the developing world as a whole has declined slightly in recent decades, in part because of increasing duration of schooling (Tzannatos 1999). For women, however, there may also be a positive participation and labor supply impact because schooling increases offered wages, hence the incentive to substitute time in the labor market for time in non-market activities or leisure (though the impact may also be negative because of the income effect associated with a higher wage). Education may also raise female participation by shaping girls' tastes for work and career. The lifetime labor supply of boys, in contrast, will be relatively inelastic to the wage rate, hence to schooling, because for men in any education category full time participation during prime working years is the norm. 
Therefore any positive effects of education on the labor supply of women would raise the internal rate of return to investing in girls' education relative to boys', tending to offset the negative effects of lower mean labor female supply. ${ }^{30}$ Empirically, in descriptive as well as multivariate analyses the relation of female labor force participation to the level of education often takes an inverted U shape: high for women with little or no schooling, lower for those with some education and then high again for those with substantial schooling (Smock 1982; Deolalikar 1993; Kingdon 1998; Glick and Sahn 1997). Among other factors, this pattern likely reflects the relative strengths of the substitution and income effects of an increasing wage as the level of schooling rises. In contrast, if one considers specifically female formal sector participation or wage employment, education has monotonically increasing effects on participation (Schultz 1993). Where labor markets are segmented, formal sector employees tend to be better compensated in terms of pay and benefits than informal sector workers with similar qualifications. Hence there may be high private returns to educating girls (and usually to boys as well) operating through effects on entry into well paying formal employment.

The foregoing discussion makes clear that from the point of view of understanding household decisions on educating girls and boys, research needs to consider gender differences in 'overall' returns to schooling comprising both effects on participation (and sector of employment and labor supply) and effects on earnings conditional on participation. Few studies of male and female earnings seem to have done this; instead, the main interest of these studies has been in comparing male and female pay controlling for labor supply and testing if additions to schooling and experience are rewarded similarly for men and women. With suitable controls for selectivity, this is appropriate for addressing questions of pay discrimination and gender differences in wage structure. But as indicated, household decisions about educating girls will also depend on girls' expected future involvement in the labor force, and how this is affected by their schooling.

With respect to policy, if private (household) schooling returns for girls are low relative to boys because their future labor supply is expected to be lower, policies that encourage greater female participation, hours of work, or continuity in employment should induce parents to invest more in the education of their daughters. In view of the constraints on women's labor force activity posed by their domestic and childcare responsibilities, one such policy--if not, precisely speaking, a labor market policy—would be to subsidize childcare services (see Glick 2002). ${ }^{31}$ Public sector support of childcare is thus uniquely situated in that it can increase incentives to

\footnotetext{
${ }^{30}$ To show this more formally, note that lifetime income or wealth equals the earnings per full time equivalent year employed (or the 'wage', denoted by W) times lifetime labor supply or years of full time work (L). Given the dependence of the wage on schooling, the private marginal labor market return to schooling (ignoring costs as well as the effects of schooling on age at entry) is $\frac{\partial(\mathrm{WL})}{\partial \mathrm{S}}=\frac{\partial \mathrm{W}}{\partial \mathrm{S}} \mathrm{L}+\frac{\partial \mathrm{L}}{\partial \mathrm{W}} \frac{\partial \mathrm{W}}{\partial \mathrm{S}} \mathrm{W}$. Because of lower mean labor supply (L) for females, the first term on the right hand side will be smaller for girls, but if schooling increases female labor supply (because $\partial \mathrm{L} / \partial \mathrm{W}>0$ ), the second term will be positive hence greater than for boys for whom, as noted in the text, it is essentially zero.

${ }^{31}$ Childcare would be an explicit labor market policy if the state required firms to provide this service to employees. This is not advisable, not just because it would be distortionary in the usual economic sense, but because it would create a strong disincentive on the part of employers to hire women (see Glick 2002 for discussion).
} 
invest in girls' education in two ways: by raising expected future labor market benefits via positive effects on female labor supply and, as seen in section 3.6, by reducing the current (opportunity) costs of sending girls to school. Note that empirically it would be hard to tell these two effects apart when examining the impacts of childcare programs. ${ }^{32}$

\section{Gender discrimination in the labor market}

Regression estimates showing that an additional year of schooling results in a smaller improvement in hourly (say) pay for women then men would imply that incentives for investing in girl's education are lower than for boys', quite apart from the labor supply considerations discussed in the previous section. Such a pattern in earnings estimates is reported by Appleton et. al. (1999) for a sample of three African countries and Kingdon (1998) for India. Also in these contexts, girls receive less education than boys. These authors hypothesize, plausibly, that the inferior rewards to education for women are a cause of low female schooling investments. Unfortunately, since there is no way in these studies to identify the counterfactual, it is unclear how much of the gender gap in schooling is due to the differences in labor market returns to schooling, and how much to differences in remittances from sons and daughters, or perhaps, to culturally determined preferences.

In fact, these cases appear to be the exception rather than the norm. In a review of the developing country earnings literature, Schultz (2002) concludes that the proportional increase in hourly earnings from an additional year of schooling (measured by the coefficient on years of schooling in a log wage regression) is typically the same or higher for women as for men, whether or not selectivity of participation is controlled for. This suggests that returns in terms of compensation are not lower for women, but note that even if the incremental effects of schooling on wages are similar, the level of pay is generally still lower for women than men throughout the developing world (though rising more rapidly for women over time; see Tzannatos 1999 and Horton 1999). Much of this gap is due to the fact that women have lower mean levels of human capital as measured by education and experience. But some may be due to pay discrimination, leading to a lower expected female wage across the distributions of education and experience. ${ }^{33}$

Lower wages mean that women will have less incentive than similarly schooled men to substitute time in the labor market for time in non-market activities, i.e., they will be less likely to enter the labor force or to work as many hours as men do. Unless this negative substitution effect is overwhelmed by the positive income effect of a lower wage, expected participation or labor supply of women will be reduced, hence so will parental returns to investing in girls' schooling via the mechanisms discussed above. ${ }^{34}$

\footnotetext{
${ }^{32}$ Though this may depend on how long the childcare policy has been in place. It may take some time before parental expectations about the future labor force participation of daughters are affected by observation of the effects of these services on current female employment. Therefore if a childcare program is recent, as it would be in the context of a policy experiment, the estimated program impacts on girl's schooling are likely to measure only the current opportunity cost effects. They will thus understate the full long term effects.

${ }^{33}$ In earnings regressions in which the incremental effects of schooling do not differ for women and men, this will occur with a sufficiently lower intercept (representing base pay) for women.

${ }^{34}$ To clarify, the similarity in female and male schooling returns in wage regressions refers to the incremental impacts of schooling on pay per hour (or month, or year) of work. The schooling investment decision, on the other
} 
Observed differences in pay for similarly skilled men and women may actually reflect not wage discrimination but discrimination in hiring for specific sectors of the labor market or in specific occupations. As with pure wage discrimination, this form of gender bias may reduce the private returns to girls' schooling through impacts on anticipated employment and labor supply. If women face barriers to employment, or if because of such barriers they can only obtain work in relatively unremunerative or unrewarding occupations or sectors of the labor market, they may opt not to be in the labor force at all or for as long as men, reducing schooling returns by the reasoning above.

Although this outcome does not require that employment discrimination be more pronounced for women with higher schooling or skills, such a pattern obviously would further reduce the household's perceived returns to investing in girls' schooling. It is not clear whether this pattern occurs. As indicated above, education improves access to formal sector employment for women, which is often better compensated than informal work. However, even if education makes well paying formal employment possible for women, implying high private returns to their education, women still face barriers to hiring in many formal sector jobs that men do not. There is evidence that formal employers are often reluctant to hire women (see Hein and Anker 1986). Rather than outright preferences for male workers, the reason may be that women are perceived to be more likely to leave or interrupt their jobs to start families or care for children, or else to experience greater absenteeism due to family obligations.

Whether due to the biases or perceptions of employers or to women's own preferences for informal work (which is generally more compatible with childcare), a lower probability of formal sector employment for educated women reduces the returns to schooling relative to what they would be otherwise and relative to returns for boys. Given the typical skill requirements for formal sector entry, this may mean in particular the returns to post-primary schooling. ${ }^{35}$ It follows that policies to increase women's representation in formal sector employment — or for that matter, their ability to enter any high-skill/high-paying profession - should raise the perceived benefits to parents of keeping girls in school longer. If employer hiring practices are the issue, regulations or legislation to prevent discrimination in hiring, provided they are adequately enforced, can achieve this goal. On the other hand, to the extent that employer preferences for men reflect accurate expectations of greater female absenteeism or employment interruptions, it would be preferable to consider interventions outside the labor market itself that permit greater continuity in women's employment. ${ }^{36}$ Once again, subsidized childcare services emerges as a potentially highly effective policy.

hand, depends on expected lifetime earnings, hence is also a function of total years of employment. This in turn depends on the level of the wage, which is lower for women when there is pay discrimination.

${ }^{35}$ Figure 5 can be used to illustrate this under the simplifying assumptions that completed primary school is a requirement for formal sector entry and there is no benefit to schooling in informal work. In this case, the girls' expected marginal returns curve lies below boys' because primary or better educated girls have a lower likelihood of admittance into the formal sector than similarly educated boys. Note that this assumes similar pay premia to formal employment for men and women.

${ }^{36}$ Interestingly, Anker and Hein (1986) show that such employer perceptions are often incorrect or exaggerated, implying somewhat counter-intuitively that interventions to insure greater continuity of women's employment are 
In many regions of the developing world women's low geographical mobility constitutes another possible barrier to entry into employment in which female schooling would pay off. Formal sector employment, unlike informal or self-employment (e.g., work on family farms) tends to be concentrated in cities or towns. If due to cultural restrictions or the demands on their time in the home women are not as free as men to migrate (or simply to commute long distances to work), they will be disadvantaged in access to formal employment even if employers would be willing to hire them. As for policy responses to this mobility constraint, several Asian countries (e.g., Taiwan and China) seem to have effectively dealt with it - perhaps not intentionally-by encouraging local level small scale industrial development in rural areas (see Schultz 2002 for discussion). These industries provide opportunities for educated women to apply their skills, thereby increasing the returns, and parental incentives, to educating girls.

An important partial exception to the association noted above of level of education and formal sector employment, and certainly to the tendency of formal employers to favor men, is the participation of women in export processing manufacturing, particularly in Asia.

Employment in export processing, at least in its early stages, is dominated by semi-skilled or low-skilled women. Although controversial for a number of reasons (see Mehra and Gammage 1999), this employment typically offers a pay premium over the informal wage or selfemployment that would be the main or only alternatives for such women (Kusago and Tzannatos 1998; Glick and Roubaud 2006). While this signifies gains for many women, the easier access of women to well paid semi-skilled formal work implies a fall in the perceived benefits to parents of keeping daughters in school beyond the level required for this work, which in many cases would be no more than a primary education. ${ }^{37}$ Discussions of the implications for women's welfare of policies promoting export processing should take into account these potential long term impacts on human capital formation.

\section{Income and time allocation effects of women's employment}

A very different way in which policies that improve earnings opportunities for women can affect girl's acquisition of human capital is by increasing women's influence over household schooling decisions. Where income is not completely pooled within the household - as has been shown to be the case for example in much of Africa (Fapohunda 1988; Munachonga 1988) - a greater share of household income earned (and controlled) by the woman implies greater spending on goods and services that she prefers. Similarly, where income is pooled, access to remunerative employment may increase a woman's bargaining power in decisions about the allocation of this income, in part because she can more credibly threaten to exit the partnership. If women also have stronger preferences than their spouses for girls' human capital, these factors imply that improvements in their labor incomes will lead to larger gains for girls relative to boys compared with equivalent increases in the income of the father. Thus is it possible, for example,

not necessary. However, observed low absenteeism and strong labor force attachment of female formal sector workers may reflect selection into the sector of women with especially strong career aspirations-or women with access to good private childcare alternatives. See Glick and Sahn (2005b).

${ }^{37}$ On the other hand, as export processing sectors move up the technological ladder, skill requirements increase. In the short term this favors men because of their higher average schooling, but also restores incentives to invest in the schooling of both boys and girls. 
that where subsidies for childcare increase both maternal employment and daughters' enrollment as in the study by Lokshin et. al. (2000), the enrollment gains for girls are due in part to greater bargaining power on the part of newly employed mothers, not just to the reduction in the domestic work burdens of girls.

Research on this question faces the challenge of the potential simultaneity of decisions regarding female labor market activity, on the one hand, and children's human capital on the other. For example, women who are themselves active in the labor market (and possibly also their spouses) may place a high priority on daughters' education and career opportunities, and this rather than a causal effect may explain an observed association of maternal income and daughter's human capital. Several studies that have compared the effect of increases in maternal schooling (rather than income) on girls' and boys' schooling or health outcomes find the gains for girls to be larger (Glick and Sahn 2000; Sahn and Stifel 2002; Thomas 1994). Since a woman's schooling should lead, via greater actual or potential earnings, to increased bargaining power vis-a-vis her spouse, these results are consistent with women having stronger preferences than men for girls' human capital. Other interpretations of these findings are possible, however (see Glick and Sahn 2000), so it remains somewhat hard to predict the gender impacts of policies to increase female involvement in income earning activities in these settings.

In contrast to these examples, Thomas (1993) assesses the effect of income directly by estimating the effects of variation in the unearned income of the mother, which is more plausibly exogenous than labor earnings to work and schooling decisions. Consistent with the research just mentioned, Thomas finds that this income has larger benefits to the nutritional status of girls than boys, while no such gender difference is seen for father's unearned income. Overall, however, while a number of studies indicate that women have stronger preferences than men for investing in children's human capital overall (summarized in Schultz 2002), there is less evidence that relative to men, women also tend to favor daughters. ${ }^{38}$

It should be noted as well that policies that increase women's employment opportunities will affect not only their incomes but also their time allocation. It is plausible that increases in women's labor supply in response to wage or employment incentives will by accompanied by substitution in domestic work of daughters' time for that of mothers. A number of ethnographic studies, in particular from Latin America (see Elson 1995 and Benería and Feldman 1992) indicate that girls' schooling suffered when their mothers entered the workforce because the girls had to take over from their mothers in the home. These studies usually covered times of economic crisis rather than periods in which wage incentives or employment access were improving, and the implications for girls' time use and schooling under the latter scenarios may be very different. Still, it is important to recognize that while labor market policies to enhance women's employment and earnings may disproportionately benefit girls through the maternal earnings/preferences link (and by raising returns via effects on girls' expected future participation and labor supply as discussed above), in some cases there may be negative impacts

\footnotetext{
${ }^{38}$ The former studies find that women's income has larger effects than men's on children's schooling and health in general (i.e., for both girls and boys). These provide a strong argument for increasing women's incomes, but not because girls will benefit more than boys.
} 
through time allocation responses. The latter would require additional measures to deal with childcare and other time constraints facing families. ${ }^{39}$

\section{Summary and Conclusions}

\subsection{Implications for policy to close schooling gender gaps}

Although there are significant methodological concerns with much existing research, several recurring, though not universal, patterns can be discerned in the literature with regard to the effects of policies on girls' schooling. A common finding is that girls' education is constrained more than boys' by the distance to school. Public investments that increase the local availability of schools are therefore likely to disproportionately benefit girls' enrollment and attainment, even though such a measure would not explicitly target girls. It is often found as well that girls' schooling is more sensitive than boys' to changes in fees and other direct costs. Where this is the case, demand side interventions that subsidize households' schooling costs will have larger benefits for girls. Some evidence suggests, further, that the demand for girls' schooling is more responsive than boys' to improvements in school quality, pointing to another route through which policy may redress gender imbalances even while not specifically targeting girls.

A simple model of parental investments in children's human capital can explain these boy-girl differences in responses to ostensibly gender-neutral education policies through appropriate assumptions about school costs and benefits, specifically with respect to curvature or discontinuities in these functions. The same outcomes could be generated by a model in which the schooling of children is viewed as a consumption good, based on assumptions about the nature of parental utility functions. Existing research generally does not allow one to distinguish these explanations, or for that matter, to distinguish between different model assumptions within the investment framework. However, one reason the latter has been emphasized in this paper is that it yields a number of interesting avenues for further research, discussed below, on the nature of the benefits and costs of girls' and boys' schooling and on parental perceptions of these benefits and costs.

Although the patterns just summarized seem well established by extensive research, this paper has also stressed the need to be wary of broad generalizations about differences in female and male schooling responses to changes in school price, distance, and quality. This was brought out by the contrast between the long list of individual published case studies showing that proximity to schools disproportionately benefits girls, on the one hand, and a systematic study of DHS surveys that found few gender differences, on the other. No similar comprehensive study exists for other school characteristics - no equivalent comparable multi-country data are available to conduct such a study - but clearly we need to be cautious in our statements about gender differences here as well.

Where gender imbalances are large or cultural barriers to female education remain strong, it will likely be more expedient for policy to directly target girls' schooling. A number of such

\footnotetext{
${ }^{39}$ See Glick (2002) for detailed discussion.
} 
interventions have had large positive impacts on female enrollment. In particular, on the demand side, several careful program evaluations indicate that households will to respond to incentives in the form of subsidies to enroll girls. On the supply side, several randomized program evaluations suggest that school managers or teachers respond to financial incentives to attract or retain female students. A few other randomized experiments involved initiatives that combined several gender targeted measures, such as having female teachers, creating girls-only schools, and reducing distances to schools deemed suitable for girls. The favorable outcomes for these programs suggest that they can be models for use elsewhere, through it remains unclear which components led to the outcomes or if all them did, or if an important element of success was interactions among them.

Other measures with potential to raise girls' schooling include the provision of separate school toilet facilities for girls and boys, flexible school schedules, the redesign of teacher training to change attitudes or behavior toward female students, and campaigns to promote girls' education. Some of these measures would serve to reverse aspects of the school environment that effectively favor boys' learning, or would make schools more acceptable environments for daughters in the eyes of parents. Others, such as flexible or double shift school sessions (and also, subsidized childcare) would address the obstacles posed by girls' typically substantial domestic work obligations. However, while informal assessments suggest that each of these policies can help girls, they have generally not been subject to rigorous evaluation in the sense used in this paper-using either randomized designs or careful statistical analysis of household surveys in combination with school or program information.

Conducting such evaluations is an important agenda for future research to guide policy.

Policies outside the education sector itself may have important implications for investments in girls' (and boys') education. The human capital investment model implies that labor market conditions will strongly influence these decisions. Although returns to education defined narrowly as the proportional increase in wages for an additional year of schooling generally appear to be no lower for women than men (and sometimes higher), expected differences by gender in participation and labor supply will also matter from the parents' perspective. This is especially the case if non-market productivity is valued less than market productivity. Policies that increase women's ability to participate in the labor force with greater continuity and in better remunerated work should increase female participation and labor supply and will thus also change expectations about girls' future participation and labor supply. In so doing, these policies will raise the private returns to investing in girls' education, even if they leave unchanged the gradient of log hourly pay with respect to years of schooling. In some cases this will require antidiscrimination measures to expand employment opportunities for women. In others, it may entail subsidizing childcare to make it easier for women to engage in wellremunerated formal employment.

Given the focus of this study, I have not addressed a series of broader issues that are likely to be relevant to the success of policies for achieving gender equity in education. These include the overall level of financial and philosophical commitment on the part of the government to meeting equity goals; the potential benefits of implementing multiple rather than isolated interventions; and the role of donor support and the implications of the increasing emphasis on sector-wide budgetary support at the expense of project funding. Kane (2004) 
argues that broad public commitment to gender equity goals is essential and further, that countries that have achieved these goals have tended to do so using a wide range of interventions. The first point is probably inarguable. However, it is hard to know whether a multiple programs approach is essential (because of important synergies between interventions) or if instead successful outcomes occurred because one or two programs were working well while the others were not effective - or if the presence of multiple interventions merely reflects high public commitment that insures effective implementation. Obviously, the application of multiple interventions across the board rules out unambiguous analysis of the effectiveness of specific programs, a point brought out in several instances above. For this reason I have not delved into this and the other broad policy questions just enumerated, but this does not mean they are not important.

\subsection{Implications for Research}

\section{Methods}

Clearly, important gaps remain in our knowledge of the gender equity impacts of many education and education-related policies. Section 3.2 briefly discussed approaches that have been used in studies considering these impacts. It is worth returning to the subject briefly here, with more of an eye on the range of approaches that could be brought to bear on the subject, even if they have not yet been applied often or at all.

In view of a number of potentially serious problems with analysis on non-experimental data, including omitted and mismeasured variables and the endogeneity of policy regressors, there is a compelling case for expanding the use of randomized community or school level experiments to evaluate education interventions. As indicated, this process is already well underway, and it would naturally extend to policies for improving female schooling. A few such interventions, like the provision of girls' schools in Pakistan and the addition of female teachers in rural India, have already been analyzed using randomized designs, while many others, such as offering flexibility in school schedules and subsidizing childcare services, have not.

Some frequently cited limitations of experiments, such as that they do not shed light on the behavioral mechanisms that underlie measured outcomes and that they typically provide information only on short term responses to interventions, often can be addressed through changes in the design and scope of the experiment. With appropriate sampling and data collection, structural modeling of behavioral pathways can be built into experiments (Duflo et. al. forthcoming); follow-up periods can be extended to measure longer term impacts (an example of this is the evaluation of PROGRESA); the study can be made large enough to encompass diverse regions or populations, reducing concerns over weak external validity. However, the last two elaborations in particular will raise costs and logistical complexity.

Where non-experimental approaches are used with no attempt to deal with selection concerns, it is clear that researchers need to be very careful about inferring causality. However, as noted, a variety of techniques exist for obtaining consistent (or at least, relatively unbiased) estimates of the impacts of policies when participation in or access to programs is not random, i.e., when key policy regressors are potentially endogenous to schooling outcomes. Development 
and refinement of these approaches is continuing; Todd (2006) provides a thorough summary. The number of applications in developing country contexts, including in education, is growing, though these have not generally had gender as a focus.

For example, using a regression analogue to difference in difference evaluation, some researchers have used household or community level panel data to estimate fixed effects models to control for time-invariant unobservable factors that may influence both policy variables and schooling outcomes (see Duflo 2001, Parker, Todd, and Wolpin 2005, and Pitt, Rosenzweig and Gibbons 1993 for examples). ${ }^{40}$ In some cases a natural experiment may suggest itself. One example of this comes from policies on maximum class size that yield sharp discontinuities in teacher-student ratios around the level at which classes must be split to avoid exceeding the maximum size. The existence of this rule permits a regression discontinuity approach to estimating the effect of class size, a potentially endogenous variable, on school attendance or learning (see Angrist and Lavy 1996 and Urquiola 2001 for examples). Another possibility might arise from sudden shifts in policies, such as elimination of school fees.

Propensity score matching is likely to be more generally applicable. As indicated, this approach compares outcomes or changes in outcomes of program recipients or program communities with those of observably similar or matched units (see Behrman, Cheng and Todd 2004; Jalan and Ravallion 2003). This and the other methods each must invoke certain assumptions to permit identification of the effects of policies. The plausibility of these assumptions will depend on the context. For example, fixed effects and difference in difference techniques must assume that unobservable factors associated with the policy variables only affect the level of the schooling outcomes, not changes in them over time. Matching methods assume that conditioning on observable characteristics is adequate to control for all differences in outcomes not caused by the program being evaluated; this would require at the least that a large number of characteristics be available for the matching. Discussion and debate on these issues is ongoing. 41

Beyond these concerns, the feasibility of applying a particular technique will often depend on the specific policy environment (e.g., the presence of a mandated maximum class size in the example above). Researchers will often have to gather additional data. This will almost always be the case for randomized experiments, whether the sampling is of schools or households; for the latter, existing household surveys are unlikely to suffice because of requirements of the timing of data collection and the need to adequately sample households in control and treatment areas chosen for the experiment. For some non-experimental studies existing household or student data may be matched to detailed information on programs. For example, Duflo combined standard Indonesian household survey (SUSENAS) data with regionspecific historical information on the country's 1970s school construction program, allowing her to calculate the extent to which specific cohorts were exposed to greater school availability,

\footnotetext{
${ }^{40}$ Unlike the within family or community fixed effects described in Section 3.2, these exploit variation over time in longitudinal data, not variation within the household or community in cross section data.

${ }^{41}$ In addition to the studies by Glazerman et al. 2003 and Cook et al. 2006 cited earlier, see the debate over the reliability of propensity score matching in the Journal of Econometrics Vol. 125, (1-2) (March-April 2005).
} 
hence to estimate the effect of availability on school attainment. For the fixed effects models described above, panel data on households or (for community fixed effects) repeated cross section survey data are required.

With regard to the nature of the data gathered, a few additional points can be made. When using household surveys for such analysis, the need to complement these data with high quality surveys of local schools and communities is obvious. For understanding gender aspects of education demand and academic achievement, school surveys should be designed to collect information specifically on school characteristics that may differentially impact girls' and boys' enrollment and learning. This practice is not common. These characteristics would include, inter alia, the share of teachers that are female and the presence of separate latrines or toilets for boys and girls. School or teacher surveys can also elicit information on teacher attitudes and behaviors toward girl students, as in the study by Lloyd et al. (1998), a rare example of where this has been done. In some countries, existing administrative data on schools collected by the education ministry may be of high quality and suitable for merging with household or individual level data. However, these school databases may not contain many variables relevant specifically to genderbased analysis, other than perhaps the number of female teachers in each school.

\section{Questions for future research}

The most obvious focus for research is to evaluate, in different environments, the effects of a range of schooling interventions on girls' and boys' educational outcomes. Beyond this, the conceptual framework and literature reviewed in this paper suggest several directions in terms of questions to be asked and data to be collected.

First, the human capital investment model suggests that a host of parental expectations shape decisions about the education of sons and daughters: expectations about labor market returns for girls and boys, remittances, the marriage market, and the probabilities of school success and continuation. Information on some of these factors is often available in household surveys. For example, it is often possible to use the data at hand to estimate labor force participation and earnings equations for women and men. This would enable researchers to consider gender differences in overall labor market returns, incorporating both expected employment and earnings outcomes. Often data are also collected on remittances from grown daughters and sons. As indicated in Section 3.9 with reference to differences in labor market returns to education by gender, the variation necessary to draw casual inferences with respect to impacts on schooling investments will generally be lacking. Still, the available information may make it possible to narrow down the list of possible reasons for gender schooling disparities. For example, if returns to schooling in the labor market are not lower for women then men, the reasons for low female schooling lie elsewhere.

Second and related to the foregoing, greater efforts should be made to incorporate analysis qualitative and/or subjective data, in particular, information on parental (and child) perceptions and expectations related to education. This is not to say that such information has not been gathered by social scientists. But economists, with their strong preferences for revealed preference approaches (i.e., demand modeling) normally have not paid a great deal of attention to these sources of information. However, there has been increasing interest in applying standard econometric tools to subjective questions in economics (Hamermesh 2004), as well in integrating 
quantitative methods with qualitative techniques that are more prominent in other social sciences (Kanbur 2003). It would add relatively little cost to include a structured perceptions questionnaire in a household survey or to conduct qualitative interviews with a subsample of households. In some cases these approaches will be able to capture aspects of schooling decisions that standard surveys cannot, for example, the importance to parents of the effects of girls' schooling on (depending on the context) future bride price, dowry, or marriage prospects, and of teacher attitudes toward girls.

Third, the range of educational outcomes considered in empirical research should be broad. Most of the research discussed in this review simply compared male and female enrollment determinants, though some also considered grade attainment. In most countries most girls as well as boys enter school; gender gaps begin or widen later, through earlier school dropout of girls. In view of this, more emphasis should be given to how policies and household factors affect school continuation decisions for girls and boys, including primary completion and transitions to secondary school.

The determinants of academic achievement (test scores) and how these differ by gender have also received relatively little attention, in large part because test score data are less common in developing countries. Yet obviously, many or even most education interventions are designed not just to increase enrollment but also to improve learning outcomes. As indicated earlier, sample selection issues may be a serious concern, especially when considering achievement at higher levels of schooling. Test score data are typically school-based, but especially at higher grades, some children - more of them girls - will have dropped out of school, while other children may never have entered school. Therefore test data would preferably be linked to random samples of children in the community or school catchment area so as to be able to model and control for selection into the male and female student samples. ${ }^{42}$ This type of analysis remains rare. Glick and Sahn (2005a) is an example using detailed school and household survey data. In the realm of policy experiments, several of the evaluations mentioned above (Banerjee et. al. 2000; Miguel, Kremer, and Thornton 2004) consider both test score outcomes and school participation effects.

Fourth, even without changing the nature of the data collected, researchers investigating schooling outcomes and gender should consider not just whether mean impacts of school price and quality differ by gender, but whether the differences depend on the level of household resources. This is a straightforward extension to the analysis but has usually not been done. Effects on girls may well differ by income. In the Bangladesh secondary school stipend program discussed above, poor girls benefited relatively little, while similar programs in Pakistan and

\footnotetext{
${ }^{42}$ Estimates of test score determinants on student samples show effects of policies on boys' and girls' learning conditional on attaining the level they are in. It could be argued that this is the population of interest for policies directed at that level; understanding potential impacts on representative samples is less useful. As conditional estimates, such results are indeed valid, but policies such as quality improvement will also affect demand for schooling and hence entry into the level. Therefore the current sample is not representative of the potential population of students if the policy were to be broadened. Understanding the process of selection via modeling of the impacts of the policy on schooling demand will help predict these 'population level' impacts, and is of interest in its own right. Note that the limitations of conditional estimates also apply to analysis of grade progression or graduation conditional on already having attained a certain level.
} 
Cambodia were much more equitable in their impacts. The issue is particularly important where gender schooling gaps are largest at lower income levels, demanding that special attention be focused on policies that raise enrollment or school continuation of girls in poorer households.

Fifth and finally, policymakers need to be to able compare the cost-effectiveness of different options for improving girls' (and boys') education outcomes. For example, how does the cost-effectiveness of intensive multi-faceted interventions such as that in rural Balochistan compare with simpler programs such as providing incentives to schools to enroll girls as in urban Quetta, or providing tuition stipends to girls as in Bangladesh? Answering these kinds of questions raises a number of challenges. First, simply comparing the effectiveness of the relevant alternatives, let alone effectiveness relative to costs, is not straightforward. As noted, we lack reliable knowledge of this for many potential interventions. Further, the impacts that have been measured may be highly country or culture specific: what is effective in Pakistan might have little impact in Guinea. A further issue is how to judge 'effectiveness' (or better, societal benefit): In terms of absolute improvements in girls' attainment? In terms of relative improvements, i.e., reductions in the gender gap? Absolute improvements for both girls and boys? Larger improvements for poor girls?

If we are concerned primarily with absolute and relative gains for girls, a broad conclusion about effectiveness can be made. Most of the gender targeted interventions reviewed above that were subject to randomized or statistically rigorous evaluation, including subsidies to families to enroll daughters, resulted in quite large absolute as well as relative gains for girls. These improvements appear generally to be larger than from non-targeted improvements, especially if one focuses on reductions in the gender gap (through reducing distance through rural school construction may be one non-targeted intervention with large relative gains for girls). At the same time, one reason targeted interventions work so well at closing gaps is that typically they have little or no benefit for boys' schooling - and potentially could have negative effects through substitution of daughters' for sons' education or through a dilution of school quality as total enrollments rise.

With regard to cost-effectiveness, analyses for individual interventions related to schooling and gender, let alone comparisons across alternatives, remain relatively rare. ${ }^{43}$ Also related to the issue of costs is the choice between interventions that target poor girls or regions, hence are cheaper, and programs with universal eligibility (all girls, or all children) that insure broader political support but may be hard to sustain fiscally. Policymakers would benefit significantly from knowledge of the implications of choosing these different options, pointing to another important direction for research. In addition, for any intervention to raise girls' schooling, the fiscal impacts need to be considered from both short and long term perspectives. As Schultz (2002) perceptively points out, policies that increase girl's education may, by increasing future female labor market participation at the expense of home production, significantly expand the tax base for governments in the long run.

\footnotetext{
${ }^{43}$ Evaluations of specific programs, for which costs are usually well defined, often do consider cost-effectiveness. Examples are Wodon's (1998) analysis of Food for Education in Bangladesh and Coady and Parker's (2002) analysis of PROGRESA.
} 


\section{References}

Ahmed, A.U., and C. del Ninno (2002). "The Food for Education Program in Bangladesh: An Evaluation of Its Impact on Educational Attainment and Food Security." Food Consumption and Nutrition Division Discussion paper No.138, International Food Policy Research Institute, Washington, DC.

Alderman, H., J. R. Behman, S. Kahn, D. Ross, and R. Sabot (1997). "The Income Gap in Cognitive Skills in Rural Pakistan." Economic Development and Cultural Change 46(1): 97-122.

Alderman, H., and E. M. King (1998). "Gender Differences in Parental Investment in Education." Structural Change and Economic Dynamics 9(4): 453-468.

Alderman, H., J. Kim, and P. F. Orazem (2003). "Design, Evaluation, and Sustainability of Private Schools for the Poor: The Pakistan Urban and Rural Fellowship School Experiments." Economics of Education Review 22(3): 265-274.

Angrist, J., E. Bettinger, E. Bloom, E. King, and M. Kremer (2002). "Vouchers for Private Schooling in Colombia: Evidence from a Randomized Natural Experiment. American Economic Review 92(5): 1535-1558.

Angrist, Joshua, and Victor Lavy (1999). "Using Maimonides' Rule to Estimate the Effect of Class Size on Children's Academic Achievement.” Quarterly Journal of Economics 114(2): 533-576.

Anker, R., and C. Hein (1985). "Why Do Third World Employers Usually Prefer Men?" International Labor Review 124: 73-90.

Appleton, S. (1995). "Exam Determinants in Kenyan Primary School: Determinants and Gender Differences." World Bank, Economic Development Institute, Washington, DC.

Appleton, S., J. Hoddinott, P. Krishnan, and M. Kerry (1999). "Does the labour market explain lower female schooling? Evidence from three African countries." In Navaretti, Giorgia B., Riccardo Faini and Giovanni Zanalda (eds) Labour Markets, Poverty and Development. Oxford: Oxford University Press, pp. 151-177.

Araujo, M., and N. Schady (2006). "Cash Transfers,Conditions, School Enrollment, and Child Work: Evidence from a Randomized Experiment in Ecuador.” Policy Research Working Paper 3930, World Bank, Washington, DC.

Banerjee, A., J. Suraj, and M. Kremer with J. Lanjouw, and P. Lanjouw (2000). "Promoting School Participation in Rural Rajasthan: Results from Some Prospective Trials." Department of Economics, Massachusetts Institute of Technology, Cambridge, MA.

Basu, A. (1997). "Sibling Rivalry, Resource Constraints, and Gender Bias in Education: Evidence from Rajasthan." Harvard University, Cambridge, MA. 
Behrman, J. R. and J. Knowles (1999). "Household Income and Child Schooling in Vietnam." The World Bank Economic Review 13(2): 211-256.

Behrman, J., Y. Cheng, and P. Todd (2004). "Evaluating Preschool Programs when Length of Exposure to the Program Varies: A Nonparametric Approach." Review of Economics and Statistics 86(1):108-132.

Bellew, R., and E. King (1993). "Educating women: Lessons from experience." In King, E., and M. A. Hill, (eds), Women's Education in Developing Countries: Barriers, Benefits, and Policies. Washington, DC: The World Bank.

Bouis, H. E., M. Palabrica-Costello, O. Solon, D. Westbrook, and A. B. Limbo (1998). "Gender Equality and Investments in Adolescents in the Rural Philippines." Research Report No. 108, International Food Policy Research Institute, Washington, DC.

Cardoso, E., and A. Portela Souza (2003). "The Impact of Cash Transfers on Child Labor and School Attendance in Brazil.” Draft, Instituto de Estudos do Trabalho e Sociedade, Brazil.

Chin, A. (2005). "Can Redistributing Teachers Across Schools Raise Educational Attainment? Evidence from Operation Blackboard in India." Journal of Development Economics 78(2): 384-405.

Coady, D., and S. Parker (2002). "A Cost-effectiveness Analysis of Demand- and Supply-side Education Interventions: The Case of PROGRESA in Mexico." Review of Development Economics 8(3): 440-451.

Colclough, C., S. Al-Samarrai, P. Rose, and M. Tembon (2003). Achieving Schooling for All in Africa: Costs, Commitment, and Gender. Aldershot, UK and Burlington, VT: Ashgate Press.

Chaudhury, N., and D. Parajuli (2006). "Conditional Cash Transfers and Female Schooling: The Impact of the Female School Stipend Program on Public School Enrollments in Punjab, Pakistan." World Bank Policy Research Working Paper No. 4102, World Bank, Washington DC.

Cook, T. D., W. R. Shadish, and V. C. Wong (2006). "Within Study Comparisons of Experiments and Non-Experiments: Can They Help Decide on Evaluation Policy." Draft, Northwestern University.

Deolalikar, A. (1998). "Primary and Secondary Education in Kenya: Sector Review." The World Bank, Washington, DC.

Deolalikar, A. (1993). "Gender Differences in the Returns to Schooling and in School Enrollment Rates in Indonesia." Journal of Human Resources 28(4): 899-932. 
DeTray, D. (1988). "Government policy, household behavior, and the distribution of schooling: A case study of Malaysia." In P. Schultz (ed), Research in Population Economics, Vol. 6. Greenwich, CT: JAI Press.

Dreze, J., and G. Kingdon (2001). "School Participation in Rural India." Review of Development Economics 5(1): 1-24.

Duflo, E. (2001). "Schooling and Labor Market Consequences of School Construction in Indonesia: Evidence from an Unusual Policy Experiment." American Economic Review 91(4): 795-813.

Duflo, E., and M. Kremer (2003). "Use of Randomization in the Evaluation of Development Effectiveness" Paper prepared for the World Bank Operations Evaluation Department (OED) Conference on Evaluation and Development Effectiveness in Washington, DC.

Duflo, E., R. Glennerster, and M. Kremer. Forthcoming "Randomization in development economics: A toolkit.” In Handbook of Development Economics, Vol 4, Elsevier.

Dupas, P. (2006). "Relative Risks and the Market for Sex:Teenagers, Sugar Daddies and HIV in Kenya.” Draft, Dartmouth College, Hanover, NH.

Engle, P. L., M. E. Pedersen, and R. Schmidt (1985). “The Effects of Maternal Employment on Children's Nutritional Status and School Participation in Rural and Urbanizing Guatemala." Report prepared for USAID.

Filmer, D. (1999). "The Structure of Social Disparities in Education: Gender and Wealth. Background Paper for Engendering Development." The World Bank, Washington, DC.

Filmer, D., and N. Schady (2006). "Getting Girls into School: Evidence from a Scholarship Program in Cambodia.” Policy Research Working Paper 3910. World Bank, Washington, DC.

Garg, A., and J. Morduch (1998). "Sibling Rivalry and the Gender Gap: Evidence from Child Health Outcomes in Ghana." Journal of Population Economics 11(4): 471-493.

Gertler, P. and P. Glewwe (1992). "The Willingness to Pay for Education of Daughters in Contrast to Sons: Evidence from Rural Peru." The World Bank Economic Review 6(1): 171-188.

Glazerman, S., D. Levy, and D. Myers (2003). Nonexperimental Replications of Social Experiments: A Systematic Review. Princeton, NJ: Mathematica Policy Research, Inc.

Glewwe, P., and M. Kremer (2006). "Schools, teachers, and education outcomes in developing countries." In Hanushek, E. and F. Welch (eds), Handbook on the Economics of Education. Amsterdam: Elsevier. 
Glick, P. (2002). "Women's Employment and Its Relation to Children's Health and Schooling in Developing countries: Conceptual Links, Empirical Evidence, and Policies." Cornell Food and Nutrition Policy Program Working Paper No. 131, Ithaca, NY. http://www.cfnpp.cornell.edu/images/wp131.pdf.

Glick, P. (2006). "Policy Impacts on Schooling Gender Gaps in Developing Countries: The Evidence and a Framework for Interpretation." Cornell Food and Nutrition Policy Program Working Paper No. 196, Ithaca, NY. http://www.cfnpp.cornell.edu/images/wp196.pdf

Glick, P., R. Saha, and S. D. Younger (2004). "Integrating Gender into Benefit Incidence and Demand Analysis." World Bank Poverty Reduction and Economic Management. Cornell Food and Nutrition Policy Program Working Paper No. 167, Ithaca, NY.

Glick, P., and D. E. Sahn (2000). "Schooling of Girls and Boys in a West African Country: The Effects of Parental Education, Income, and Household Structure." Economics of Education Review 19(1): 63-87.

Glick, P., and D. E. Sahn (2005). "Cognitive Skills among Children in Senegal: Disentangling the Roles of Schooling and Family Background." Cornell Food and Nutrition Policy Program Working Paper No. 189, Ithaca, NY.

Glick, P, and F. Roubaud (2006). "Export Processing Zone Expansion in Madagascar: What Are the Labor Market and Gender Impacts?” Journal of African Economies15(4): 722-756.

Hallman, K., and S. Peracca, Forthcoming. "Indigenous girls in Guatemala: Poverty and location." In Lewis, M. and Lockheed, (eds) Exclusion, Gender and Schooling: Case Studies from the Developing World. Washington, D.C.: Center for Global Development.

Hamermesh, D.S. (2004). "Subjective Outcomes in Economics." Southern Economic Journal 71(1): 2-11.

Hazarika, G. (2001). "The Sensitivity of Primary School Enrollment to the Costs of Postprimary Schooling in Rural Pakistan.” Education Economics 9(3): 237-244.

Heckman, J. J., and J.A. Smith (1995). "Assessing the Case for Social Experiments." Journal of Economic Perspectives 9(2): 85-110.

Herz, B., and G. Sperling (2004). "What Works in Girls' Education: Evidence and Policies from the Developing World." Council on Foreign Relations.

Herz, B., K. Subbarao, M. Habib, and L. Raney (1991). "Letting Girls Learn: Promising Approaches in Primary and Secondary Education." World Bank Discussion Paper No. 133. The World Bank, Washington, DC. 
Horton, S. (1999). "Marginalization Revisited: Women's Work and Pay, and Economic Development." World Development 27(3): 571-582.

Jalan, J., and M. Ravallion (2003). "Does Piped Water Reduce Diarrhea for Children in Rural India??” Journal of Econometrics 112(1): 153-173.

Kanbur, R., ed. (2003). Q-Squared: Qualitative and Quantitative Methods of Poverty Appraisal. Delhi: Permanent Black.

Kane, E. (2004). “ 'Girls' Education in Africa: What Do We Know about Strategies that Work? Successful Strategies in Improving Girls' Education in Africa." Africa Region Human Development Working Paper Series, The World Bank.

Khandker, S. R. (1996). "Education Achievements and School Efficiency in Rural Bangladesh." World Bank Discussion Paper 319, Washington, DC.

Khandker, S, M. Pitt, and N. Fuwa (2003). "Subsidy to Promote Girls' Secondary Education: the Female Stipend Program in Bangladesh." World Bank, Washington, DC.

Kim, J., H. Alderman, and P. Orazem (1998). "Can Cultural Barriers Be Overcome in Girls' Schooling? The Community Support Program in Rural Balochistan." Impact Evaluation of Education Reforms Working Paper 10, World Bank, Washington, DC. . (1999). "Can Private School Subsidies Increase Enrollment for the Poor? The Quetta Urban Fellowship Program.” World Bank Economic Review 13(3): 443-65.

King, E. M., L. A. Lillard (1987). "Education Policy and Schooling Attainment in Malaysia and the Philippines." Economics of Education Review 6(2): 167-181.

King, E. M., P. F. Orazem, and E. M. Paterno (1999). "Promotion with and without Learning: Effects on Student Dropout." Impact Evaluation of Education Reforms Working Paper 18, World Bank, Washington, DC.

Kingdon, G. (1998). "Does the Labour Market Explain Lower Female Schooling in. India?" Journal of Development Studies 35(1): 39-65.

Kremer, M., E. Miguel, and R. Thornton (2004). "Incentives to Learn.” Draft, Harvard University.

Kusago, T, and Z. Tzannatos (1998). "Export Processing Zones: A Review in Need of Update" Social Protection Discussion Paper No. 9802, World Bank, Washington, DC.

Lavy, V. (1996). "School Supply Constraints and Children's Educational Outcomes in Rural Ghana." Journal of Development Economics 51(2): 291-314. 
Levison, D., and K. Moe (1998). "Household Work as a Deterrent to Schooling: An Analysis of Adolescent Girls in Peru." The Journal of Developing Areas 32(3): 339-356.

Lloyd, C. B., ed. (2005). "Growing Up Global: The Changing Transitions to Adulthood in Developing Countries." National Research Council and Institute of Medicine of the National Academies. The National Academies Press, Washington, DC.

Lloyd, C. B., and B. S. Mensch (2006). "Marriage and Childbirth as Factors in School Exit: An Analysis of DHS Data from Sub-Saharan Africa." Population Council Working Paper 219.

Lloyd, C. B., S. El Tawila, W. H. Clark, and B. S. Mensch (2003). "The Impact of Educational Quality on School Exit in Egypt." Comparative Education Review 47(4): 444-467.

Lloyd, C. B., B. S. Mensch, and W. H. Clark (2000). "The Effects of Primary School Quality on the Educational Participation and Attainment of Kenyan Girls and Boys." Comparative Education Review 44(2): 113-147.

Lloyd, C. B., C. Mete, C., and Z. A. Sathar (2005). "The Effect of Gender Differences in Primary School Access, Type, and Quality on the Decision to Enroll in Rural Pakistan." Economic Development and Cultural Change 53(3): 685-710.

Lewis, M., and M. E. Lockheed (2006). Inexcusable Absence. Washington: Center for Global Development.

Lokshin, M., E. Glinskaya, and M. Garcia (2004). "The Effect of Early Childhood Development Programs on Women's Labor Force Participation and Older Children's Schooling in Kenya." Journal of African Economies 13(2): 111-137.

Maluccio, J. A. (2003). "Education and child labor: Experimental evidence from a Nicaraguan conditional cash transfer program.” In Orazem, P. F., G. Sedlacek, and Z. Tzannatos (eds), Child Labor and Education in Latin America. Washington, DC: InterAmerican Development Bank and The World Bank.

Mehra, R. and S. Gammage (1999). "Trends, Countertrends, and Gaps in Women's Employment." World Development 27(3): 533-550.

Michaelowa, K. (2001). "Primary Education Quality in Francophone Sub-Saharan Africa: Determinants of Learning Achievement and Efficiency Considerations." World Development 29(10): 1699-1716.

Miller-Grandvaux, Y., and K. Yoder (2002). "A Literature Review of Community Schools in Africa." USAID Bureau for Africa, Washington, DC. 
Mingat, A., and B. Suchaut (1998). "Une analyse economique comparative des systèmes educatifs Africains." Institut de Recherche sur l'Economie de l'Education (IREDU), Université de Bourgogne.

Morley, S., and D. Coady (2003). "From Social Assistance to Social Development: Targeted Education Subsidies in Developing Countries." Washington, DC: Center for Global Development.

National Research Council and Institute of Medicine of the National Academies (2003). "Growing up Global: The Changing Transitions to Adulthood in Developing Countries." Lloyd, Cynthia B. (ed.), Washington, DC: The National Academies Press.

Nieves, I. (1981). “A Balancing Act: Strategies to Cope with Work and Mmotherhood in Developing Countries." Paper presented at the ICRW Policy Round Table, The Interface between Poor Women's Nurturing Roles and Productive Responsibilities. Washington, DC: The International Center for Research on Women.

OXFAM (2003). "A Fair Chance: Attaining Gender Equality in Basic Education by 2005.” Global Campaign for Education Briefing Paper. http://www.oxfam.org.uk/what we do/issues/education/gce afairchance.htm

Parker, S., P. Todd, and K. Wolpin. (2005). "Within Family Treatment Effect Estimators: The Impact of Oportunidades on Schooling in Mexico." Manuscript, University of Pennsylvania.

Pitt, M., and M. Rosenzweig (1990). "Estimating the Intrahousehold Incidence of Illness: Child Health and Gender Inequality in the Allocation of Time." International Economic Review 31(4): 1139-1156.

Pitt, M., M. R. Rosenzweig, and D. M. Gibbons (1993). "The Determinants and Consequences of the. Placement of Government Programs in Indonesia." World Bank Economic Review 7(3): 319-348.

Ravallion, M., and Q. Wodon. (2000). "Does Child Labor Displace Schooling? Evidence on Behavioral Responses to an Enrollment Subsidy." Economic Journal 110(462): C158175.

Rosenzweig, M. R., and T. P. Schultz (1982). "Market Opportunities, Genetic Endowments and Intrafamily Resource Distribution: Child Survival in Rural India." American Economic Review 72(4): 803-815.

Safilios-Rothschild, C. (1980). "The role of the family: A neglected aspect of poverty." In Implementing Programs of Rural Development. World Bank Staff Working Paper No. 403, The World Bank, Washington, DC. 
Shapiro, D., and B.O. Tambashe (2001). "Gender, Poverty, Family Structure, and Investments in Children's Education in Kinshasa, Congo." Economics of Education Review 20(4): 35975.

Schultz, T. P. (1985). "School expenditures and enrollments, 1960-1980: The effects of income, prices, and population." In. Johnson, D. and R. Lee (eds), Population Growth and Economic Development. Madison, WI: University of Wisconsin Press.

(1993). "Investments in the Schooling and Health of Women and Men: Quantities and Returns." Journal of Human Resources 28(4): 694-734.

(2002). "Why Governments Should Invest More to Educate Girls." World Development 30(2): 207-225.

(2004). "School Subsidies for the Poor: Evaluating the Mexican Progresa Poverty Program.” Journal of Development Economics 74(1): 199-250.

Sipahimalani, V. (1999). "Education in the Rural Indian Household: The Impact of Household and School Characteristics on Gender Differences." Working Paper 68, National Council of Applied Economic Research, New Delhi.

Skoufias, E. (2001). "PROGRESA and Its Impacts on the Human Capital and Welfare of Households in Rural Mexico: A Synthesis of the Results of an Evaluation by IFPRI." December. International Food Policy Research Institute, Washington, DC.

Smock, A. (1982). "Sex differences in educational opportunities and labor force participation in six countries." In Altbach, P., and G. Kelly (eds) Comparative Education. New York: Macmillan, pp. 235-51.

Stash, S., and E. Hannum (2001). "Who Goes to School? Educational Stratification by Gender, Caste and Ethnicity in Nepal." Comparative Education Review 45(3): 354-78.

Stifel, D. and D. E. Sahn (2002). "Parental Preferences for Nutrition of Boys and Girls: Evidence from Africa." Journal of Development Studies 39(1): 21-45.

Strauss, J., and D. Thomas (1995). "Human resources: Empirical modeling of household and family decisions." In Srinivasan, T. N., and J. Behrman, (eds), Handbook of Development Economics, Vol. 3. Amsterdam: North-Holland.

Tansel, A. (1997). "School Attainment, Parental Education, and Gender in Côte d'Ivoire and Ghana." Economic Development and Cultural Change 45(4): 825-56.

(2002). "Determinants of School Attainment of Boys and Girls in Turkey: Individual, Household and Community Factors." Economics of Education Review 21(5): 455-570. 
Thomas, D. (1993). "The distribution of income and expenditure within the household." Annales de Economie et de Statistiques 29: 109-136.

Thomas, D. (1994). "Like Father, Like Son; Like Mother, Like Daughter: Parental Resources and Child Height." Journal of Human Resources 29(4): 950-988.

Todd, P. (2006) Evaluating Social Programs with Endogenous Program. Placement and Selection of the Treated. Manuscript, University of Pennsylvania

Tzannatos, Z. (1999). "Women and Labor Market Changes in the Global Economy: Growth Helps, Inequalities Hurt and Public Policy Matters.” World Development 27(3): 551-569.

Urquiola, M. (2001). "Identifying Class Size Effects in Developing Countries: Evidence from Rural Schools in Bolivia.” World Bank Development Research Group Policy Research Working Paper 2711, The World Bank, Washington, DC.

U.S. Agency for International Development (1999). CDIE Impact Evaluation: Promoting Primary Education for Girls in Guinea. Washington, DC: USAID.

Wodon, Q. (1998). Cost-Benefit Analysis of Food for Education in Bangladesh. Washington, DC: World Bank.

World Bank (2001). Engendering Development: Through Gender Equality in Rights, Resources, and Voice. World Bank Policy Research Report Series. New York and Oxford: Oxford University Press. 


\begin{tabular}{|c|c|c|c|c|c|c|c|}
\hline & \multicolumn{4}{|c|}{ Primary } & \multicolumn{3}{|c|}{ Secondary } \\
\hline & $\begin{array}{c}\text { Net } \\
\text { enrollment } \\
\text { ratio }^{\mathrm{a}}\end{array}$ & $\begin{array}{c}\text { Gross } \\
\text { enrollment } \\
\text { ratio }^{b}\end{array}$ & $\begin{array}{l}\text { Ratio of } \\
\text { female to } \\
\text { male } \\
\text { enrollments }\end{array}$ & $\begin{array}{c}\text { Ratio of } \\
\text { female to } \\
\text { male } \\
\text { completion }^{\text {rates }} \\
\text { re }\end{array}$ & $\begin{array}{c}\text { Net } \\
\text { enrollment } \\
\text { ratio }^{\mathrm{a}}\end{array}$ & $\begin{array}{c}\text { Gross } \\
\text { enrollment } \\
\text { ratio }^{\mathrm{b}}\end{array}$ & $\begin{array}{l}\text { Ratio of } \\
\text { female to } \\
\text { male } \\
\text { enrollments }\end{array}$ \\
\hline Sub-Saharan Africa & 66.9 & 93.0 & 86.2 & 84.5 & 28.0 & 33.0 & 75.1 \\
\hline East Asia \& Pacific & 87.8 & 100.5 & 88.7 & 97.0 & 46.8 & 48.3 & 81.8 \\
\hline Europe \& Central Asia & 88.8 & 99.1 & 93.8 & 96.0 & 82.4 & 88.6 & 99.2 \\
\hline $\begin{array}{l}\text { Latin America \& } \\
\text { Caribbean } \\
\text { Middle East \& North }\end{array}$ & 91.5 & 108.9 & 93.8 & 108.1 & 56.8 & 69.0 & 102.4 \\
\hline Africa & 81.6 & 99.1 & 86.9 & 93.3 & 61.2 & 67.3 & 86.9 \\
\hline South Asia & .. & 99.0 & 85.2 & 84.5 & .. & 54.4 & 80.8 \\
\hline
\end{tabular}

Source: UNESCO education statistics

Notes:

${ }^{a}$ Net enrollment =primary (or secondary) enrollments of primary (or secondary) school age children divided by number of primary (secondary) age children $\mathrm{x} 100$

${ }^{\mathrm{b}}$ Gross enrollment = total primary (or secondary) enrollments divided by number of primary (or secondary) age children $\mathrm{x} 100$.

${ }^{c}$ Completion rate $=$ number of students completing the last year of primary over the number of children of official graduation age 
Figure 1 - Differential benefits to schooling by gender: effects of a price reduction

Total costs (TC),

Total benefits (TB)

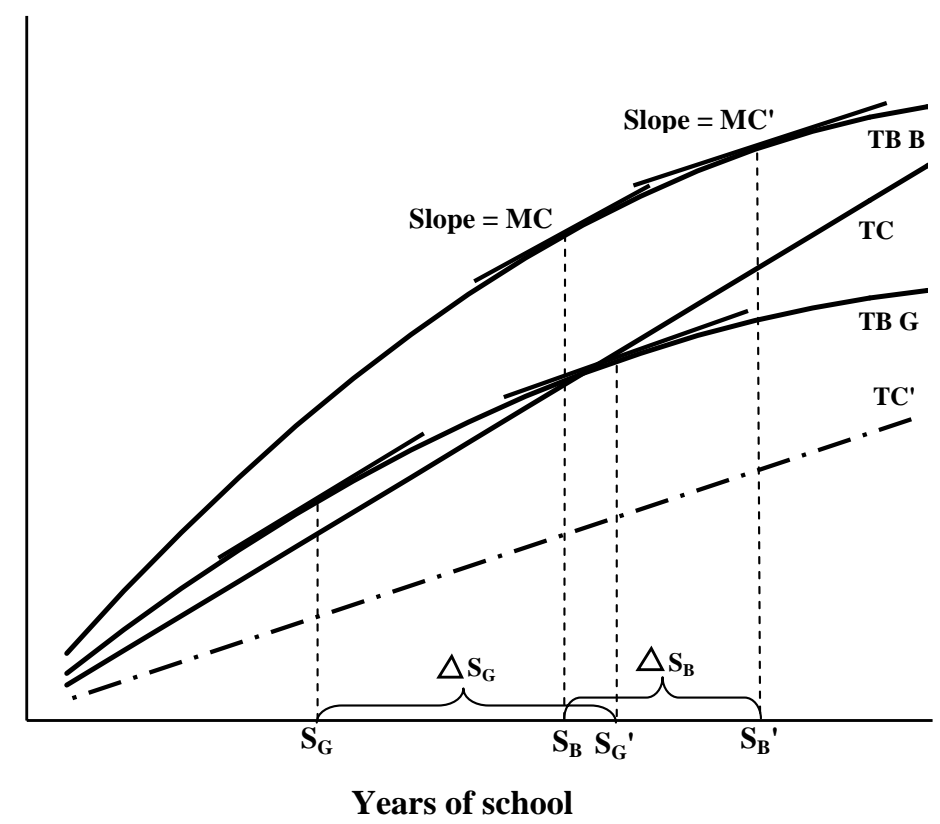

Marginal costs (MC),

Marginal benefits (MB)

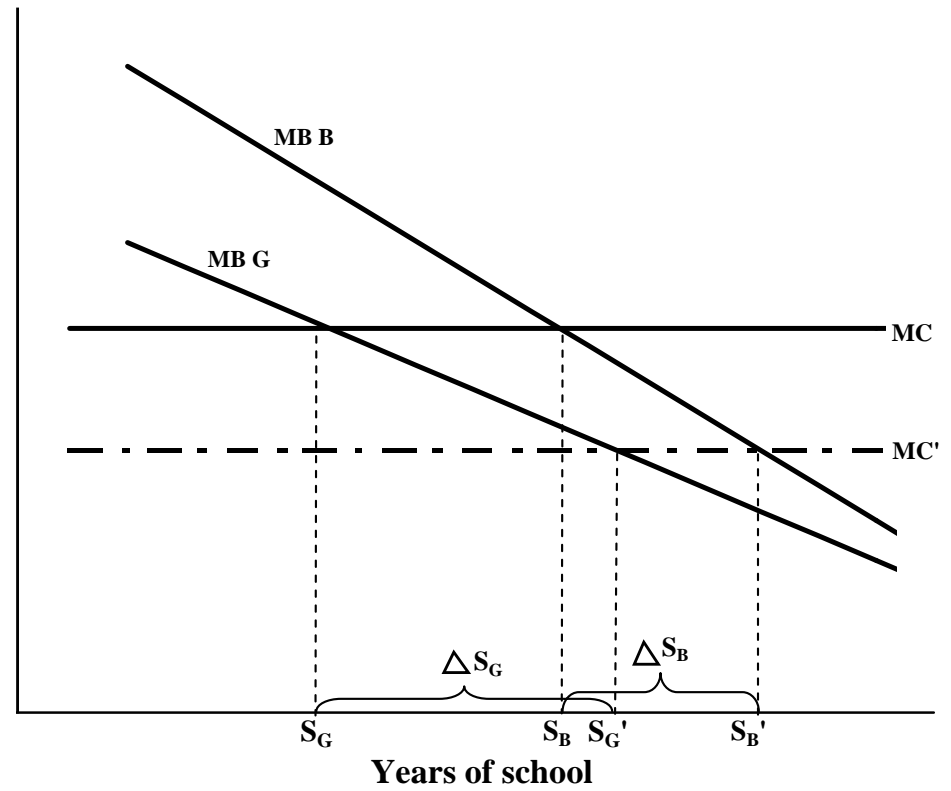

$G$ and $B$ denote girls and boys, respectively. No letter means the cost or benefit function is the same for girls and boys. Dotted lines indicate the cost or benefit functions after the indicated policy change. 
Figure 2 - Differential cost functions by gender: effects of an increase in schooling returns

Total costs,

Total benefits

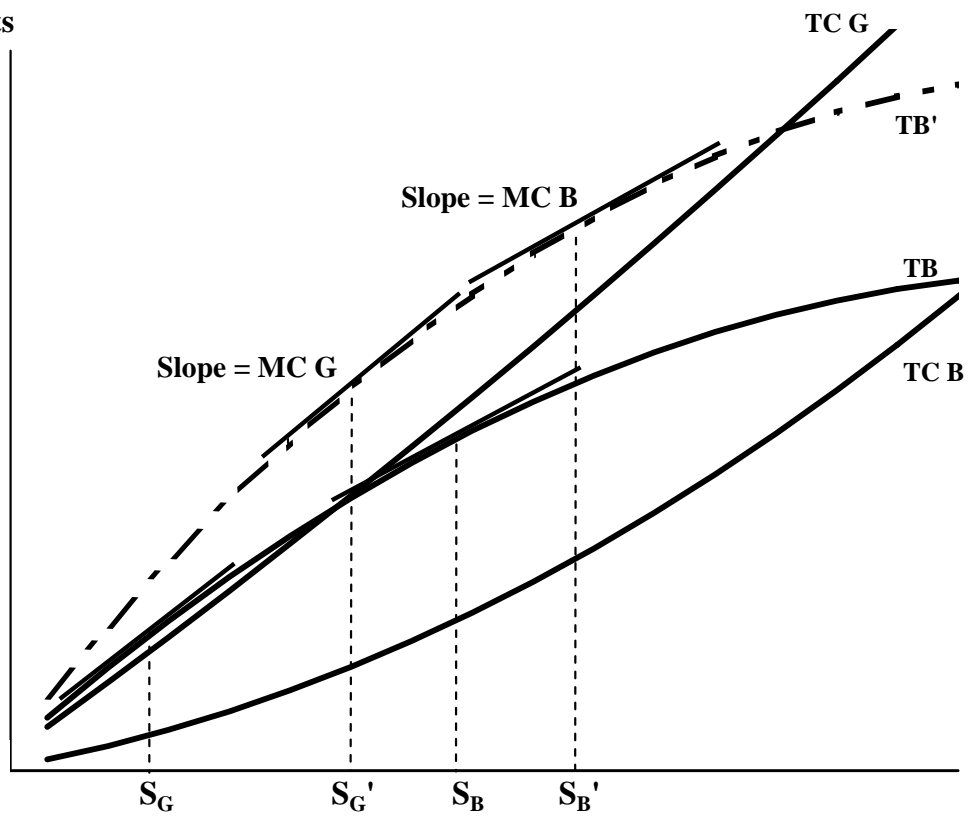

Years of school

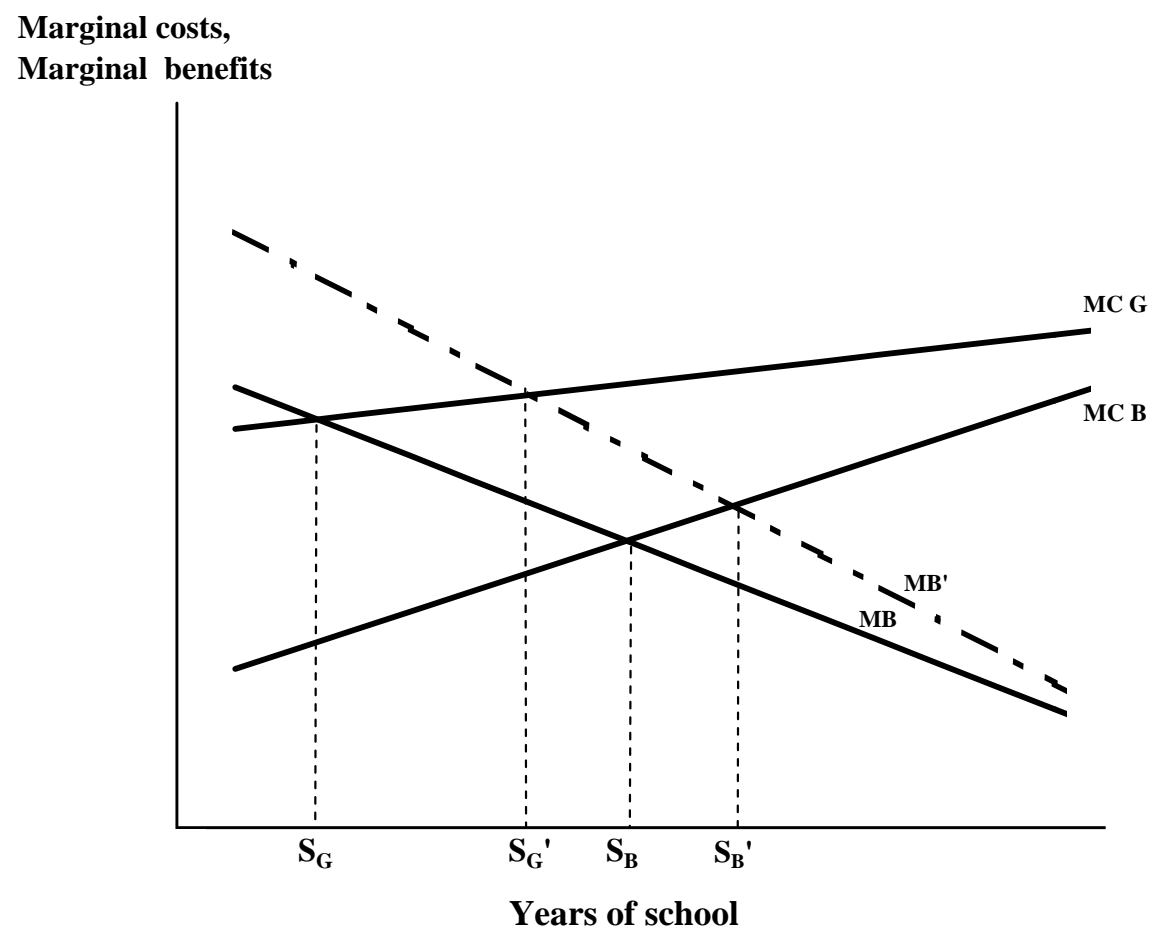


Figure 3 - Discontinuous schooling returns: effects of an increase in returns

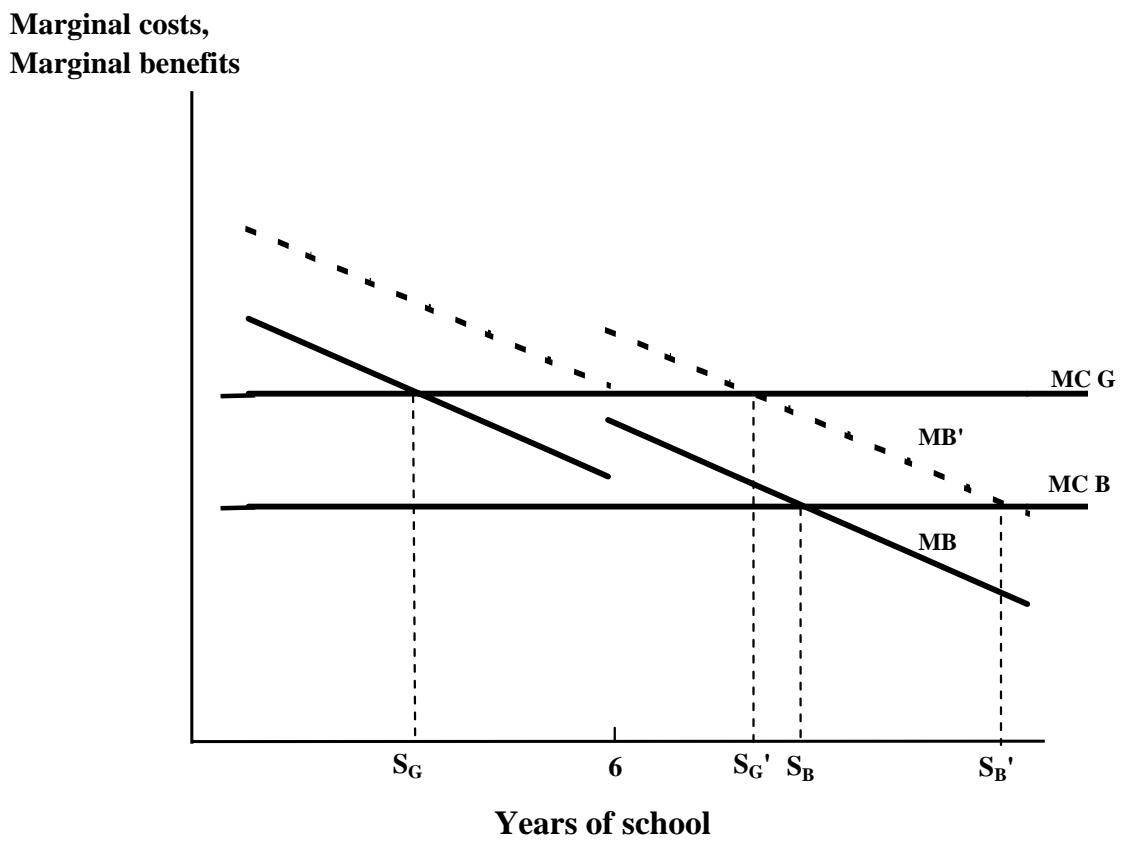

Figure 4 - Discontinuous schooling costs: effects of an increase in returns

Marginal costs,

Marginal benefits

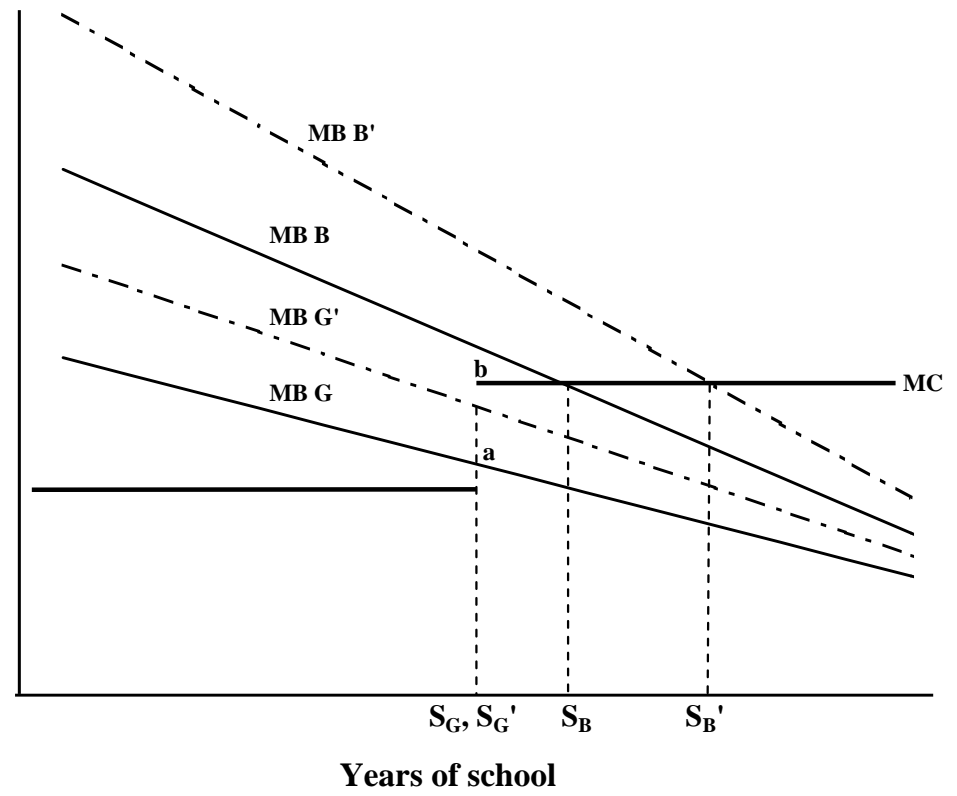


Figure 5 - Differential school progression probabilities with discontinuous returns: effects of a price reduction

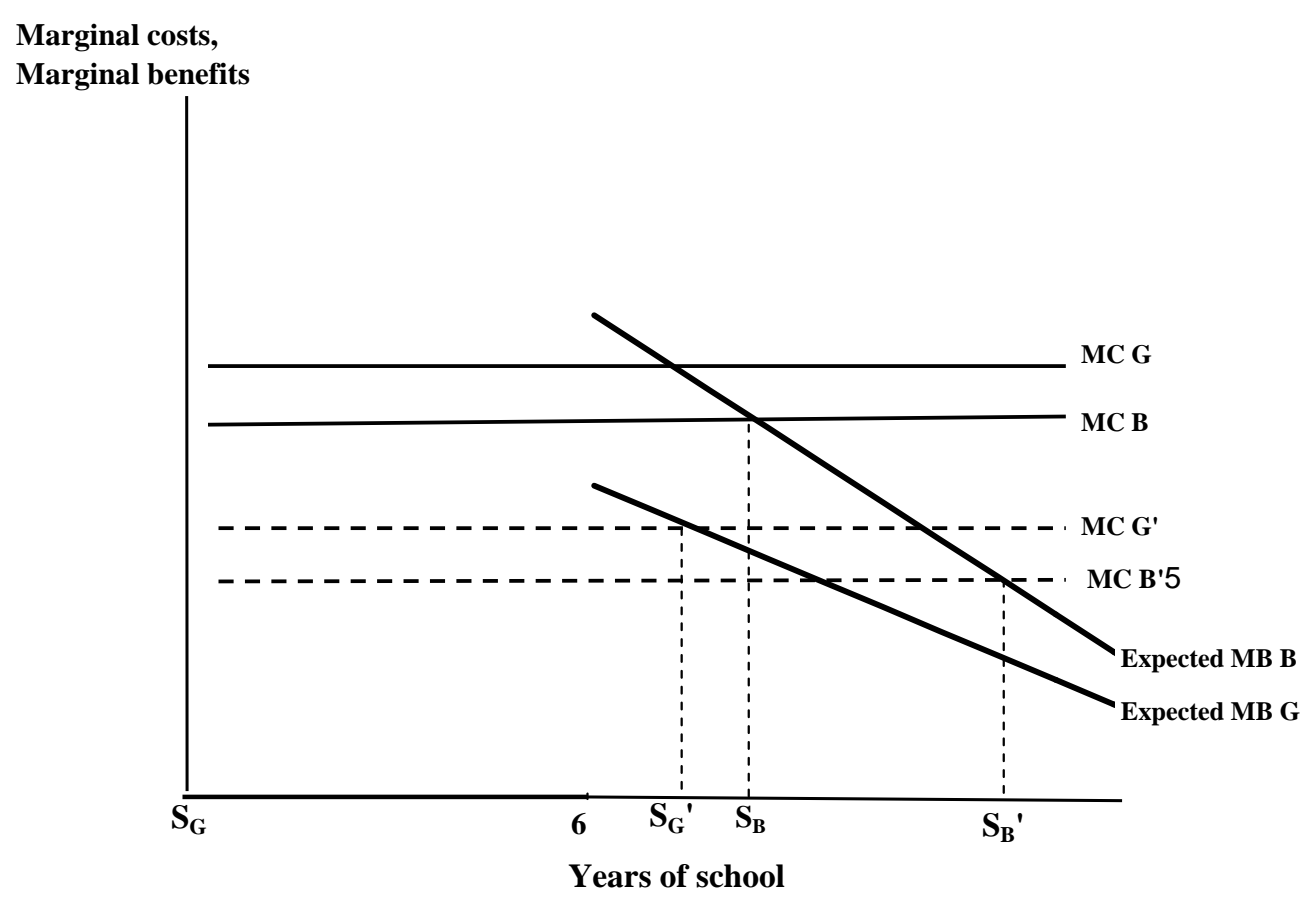

